\title{
Article
}

\section{Intelligent Anomaly Identification of Uplift Pressure Monitoring Data and Structural Diagnosis of Concrete Dam}

\author{
Chunhui Ma*Did, Tianhao Zhao, Gaochao Li, Anan Zhang and Lin Cheng
}

check for

updates

Citation: Ma, C.; Zhao, T.; Li, G.; Zhang, A.; Cheng, L. Intelligent Anomaly Identification of Uplift Pressure Monitoring Data and Structural Diagnosis of Concrete Dam. Appl. Sci. 2022, 12, 612. https://doi.org/10.3390/ app12020612

Academic Editors: Mariusz Jaśniok, Maria Sozanska and

Zbigniew Perkowski

Received: 27 November 2021

Accepted: 6 January 2022

Published: 9 January 2022

Publisher's Note: MDPI stays neutral with regard to jurisdictional claims in published maps and institutional affiliations.

Copyright: (c) 2022 by the authors. Licensee MDPI, Basel, Switzerland. This article is an open access article distributed under the terms and conditions of the Creative Commons Attribution (CC BY) license (https:/ / creativecommons.org/licenses/by/ $4.0 /)$.

\author{
State Key Laboratory of Eco-Hydraulics in Northwest Arid Region of China, Institute of Water Resources and \\ Hydroelectric Engineering, Xi'an University of Technology, Xi'an 710048, China; \\ zhaotianhao@stu.xaut.edu.cn (T.Z.); 1200412038@stu.xaut.edu.cn (G.L.); 1190412047@stu.xaut.edu.cn (A.Z.); \\ chenglin@xaut.edu.cn (L.C.) \\ * Correspondence: machunhui@xaut.edu.cn
}

\begin{abstract}
As an essential load of the concrete dam, the abnormal change of uplift pressure directly threatens the safety and stability of the concrete dam. Therefore, it is of great significance to accurately and efficiently excavate the hidden information of the uplift pressure monitoring data to clarify the safety state of the concrete dam. Therefore, in this paper, density-based spatial clustering of applications with noise (DBSCAN) method is used to intelligently identify the abnormal occurrence point and abnormal stable stage in the monitoring data. Then, an application method of measured uplift pressure is put forward to accurately reflect the spatial distribution and abnormal position of uplift pressure in the dam foundation. It is easy to calculate and connect with the finite element method through self-written software. Finally, the measured uplift pressure is applied to the finite element model of the concrete dam. By comparing the structural behavior of the concrete dam under the design and measured uplift pressure, the influence of abnormal uplift pressure on the safety state of the concrete dam is clarified, which can guide the project operation. Taking a $98.5 \mathrm{~m}$ concrete arch dam in western China as an example, the above analysis ideas and calculation methods have been verified. The abnormal identification method and uplift pressure applying method can provide ideas and tools for the structural diagnosis of a concrete dam.
\end{abstract}

Keywords: concrete dam; uplift pressure; anomaly identification; DBSCAN; structural diagnosis

\section{Introduction}

With the development of clean energy globally, the new site selection of water conservancy, hydropower, and pumped storage projects faces more complex terrain and geological conditions. At the same time, existing projects are aging and constantly challenge the limit of traditional dam design experience and material safety [1]. Therefore, it is of great significance to accurately and efficiently excavate the hidden information of the uplift pressure monitoring data [2] and clarify the safety state of the concrete dam to reduce the hidden dangers of reservoir dam engineering [3]. In 1959, the Malpasset arch dam in France suffered dam failure due to the sliding of the dam shoulder under the high water level, resulting in 421 deaths and property losses of 30 billion francs. Due to this, many researchers and engineers should attach great importance to the uplift pressure of concrete dams [4]. As an essential load of concrete dams, uplift pressure significantly influences the stress, deformation, and stability of the concrete dam [5].

In the process of concrete dam design, uplift pressure statistical analysis is usually carried out according to the existing dams, and the value and distribution of uplift pressure are determined in combination with design experience [6]. However, due to the complex distribution of cracks in the dam foundation and the concealment of seepage control measures, the real value and distribution of the uplift pressure of the concrete dam are affected by many factors, which are relatively different from the design. Rochon-Cyr et al. [7] studied the influence mechanism of uplift pressure on a concrete gravity dam by 
model test, and they think the uplift pressures must be considered in the original design. Especially for the concrete gravity dam with crack, the influence of uplift pressure on the stress intensity factor and crack propagation angle was significant through the research by Plizzari [8]. Pekau et al. [9], Alliard et al. [10], and Javanmardi et al. [11] analyzed the variation of uplift pressure under an earthquake, which is very unfavorable to the stability of the cracked dam. Mostafaei et al. [12] and Liu et al. [13] proved uplift pressure plays a vital role in the stability analysis of dam abutment by the finite element method (FEM). Furthermore, Ganji et al. [14] used the fluid-solid coupling method to analyze the safety and stability of a gravity dam under uplift pressure. Chen et al. [15] discussed different uplift pressure simulation methods, and the equivalent uplift pressure simulation method is feasible under complex situations. Fu et al. [16] research the reason for the abnormal uplift pressure of the Huaguangtan dam using the orehole video tests and numerical simulation. As described in [17], the influence of uplift pressure on dam stress can exceed $30 \%$, and the influence scope can exceed 20\%. Excessive uplift pressure leads to instability of underground structures [18]. Thus, practical uplift pressure should be applied when analyzing concrete structures.

On the other hand, some scholars have studied the anomaly identification of uplift pressure during the operation period of concrete dams, and the applicability of various anomaly identification methods is compared [19]. The membership cloud method was proposed for identifying abnormal data by Zhu et al. [20], and the uplift pressure monitoring data of the Gongzui gravity dam is identified. Hu et al. [21] constructed a time series anomaly identification method, combining dynamic time distortion and local outlier factors, to find out the local uplift of the Xixi dam foundation. Then, Hu et al. [22] integrated statistical analyses, inversion analyses, and field investigations to explain the causes of sudden increases of uplift pressures. A hybrid prediction model and supervised learning method, for outlier identification of dam monitoring data, were built by Park [23]. An online robust identification method, combining robust statistics and confidence interval, was established and applied to identify anomaly uplift pressure of the Tongjiezi Gravity Dam by Li et al. [24]. Salazar et al. [25] detected abnormal values early by an enhanced regression tree, applying to a $100 \mathrm{~m}$ high arch dam. Su et al. [26] used the density-based spatial clustering of applications with noise (DBSCAN) to identify and filter abnormal values of monitoring equipment and reduce random errors. Cheng et al. [27] identified abnormal uplift pressure data of the gravity dam by the kernel density estimation method. Furthermore, Li et al. [28], Zhu et al. [29], and Granrut et al. [30] constructed intelligent monitoring models to quickly and accurately predict the uplift pressure of the dam, realizing the early warning and forecast of uplift pressure. These abnormal identification models of uplift pressure are mostly extended from the dam displacement model. Therefore, it fails to conduct comprehensive and systematic research on the occurrence, application, and influence of abnormal uplift pressure.

The studies mentioned above, on the influence mechanism and influence degree of uplift pressure, are primarily based on design parameters. Aiming at the shortages existing in the above research, this study will focus on the abnormal uplift pressure of concrete dams during the operation period. A series of studies on the safety state of concrete dams is carried out from anomaly identification, uplift pressure application method, structural numerical simulation, and structural diagnosis. This study has essential scientific research value and practical engineering significance for the safe operation of concrete structures.

\section{Intelligent Anomaly Identification Model of Uplift Pressure \\ 2.1. Principles of the DBSCAN}

As a machine learning algorithm, the DBSCAN is an unsupervised intelligent clustering algorithm [31]. The DBSCAN can divide data with high density and irregular shape into clusters, which is widely used in tracks [32], medical treatment [33], teaching [34], modal identification [35], and other fields of anomaly identification and early diagnosis. Compared with conventional clustering methods such as K-means, DBSCAN has many 
advantages, such as no need to specify the number of clusters in advance, being unaffected by initial values, finding clusters with arbitrary shapes, and identifying noise points [36].

The DBSCAN algorithm starts from a selected core point and continuously expands to the area with attainable density, to obtain a maximized area containing core points and boundary points. The calculation flow is shown in Figure 1, and more detailed calculation procedures can be found in the literature [31].

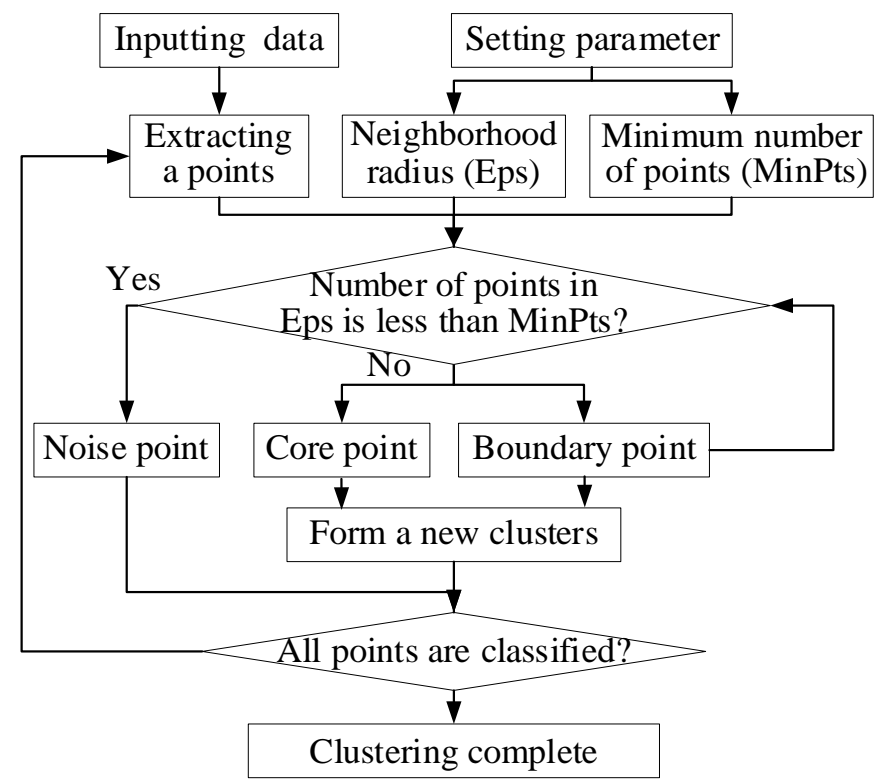

Figure 1. Flow chart of DBSCAN algorithm.

\subsection{Anomaly Identification Model of Uplift Pressure Based on DBSCAN}

Through the above analysis about the advantages and disadvantages of the DBSCAN, it can be known that the DBSCAN unsupervised clustering algorithm has good applicability for the identification of abnormal uplift pressure data: (1) the abnormal occurrence data of uplift pressure usually appear in the conversion process of different states. The DBSCAN can precisely identify noise points between different clusters, which respond well to the occurrence characteristics of abnormal monitoring data. (2) Given that the uplift pressure is closely related to the reservoir water level, and it presents similar one-to-one correspondence characteristics, the DBSCAN can identify classes with arbitrary shapes [37], so it can precisely identify the monitoring data clustering of the uplift pressure in the normal and the abnormally stable state. (3) For data with high-dimensional, uneven density and large distance, the clustering effect of the DBSCAN will be worse. The above problems have not occurred in uplift pressure monitoring data because of the reservoir operation mode and monitoring method. Therefore, the anomaly identification model of the uplift pressure proposed in this paper can use the advantages of the DBSCAN algorithm and avoid its defects. This anomaly identification model has good applicability to the uplift pressure, of which the calculation flow is shown in Figure 2. 


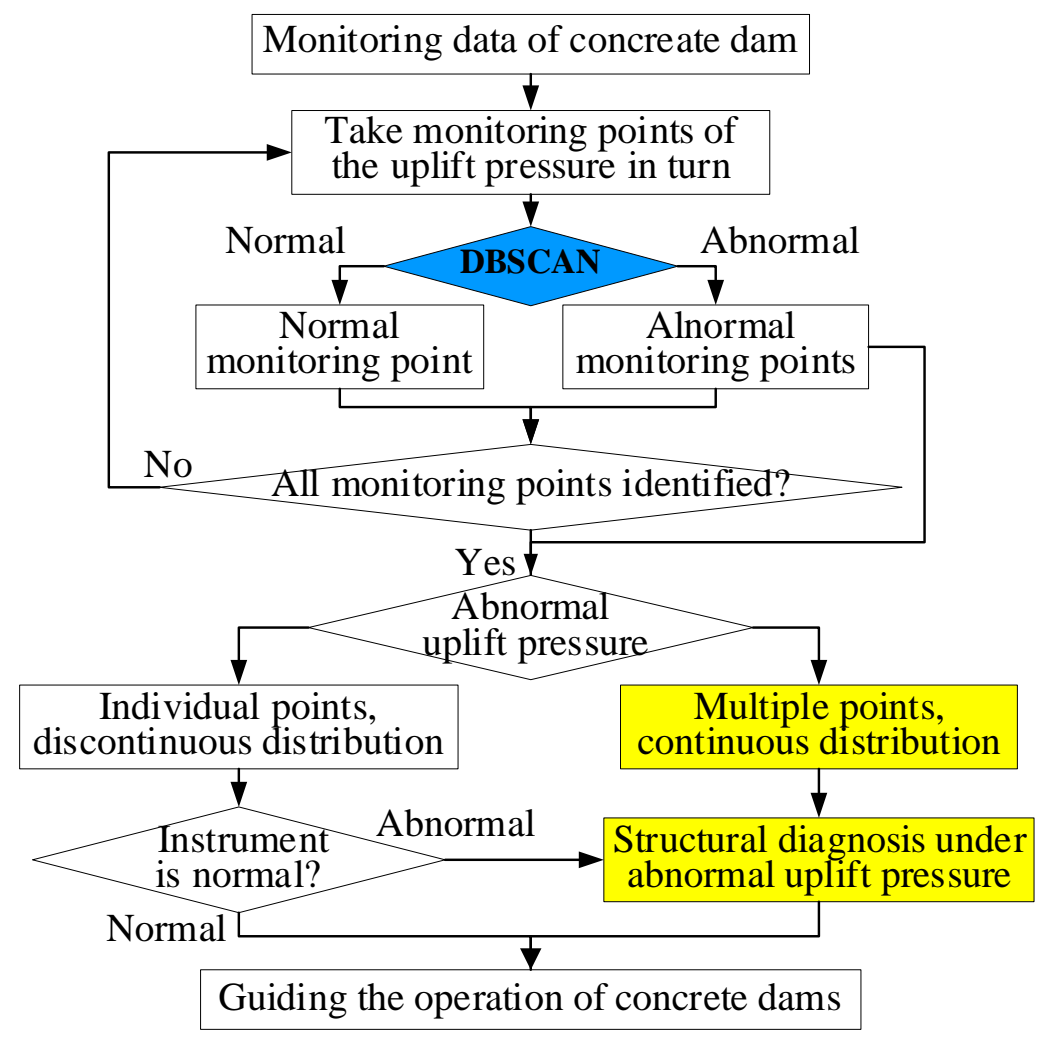

Figure 2. Flow chart of anomaly identification model of uplift pressure, based on DBSCAN.

The calculation steps of the anomaly identification model of uplift pressure based on DBSCAN are as follows:

(1) Normalizing the monitoring data of upstream water level and uplift pressure of the concrete dam can fully reflect the monitoring data characteristics.

(2) The DBSCAN algorithm is used to identify monitoring points of the uplift pressure one by one. According to the identification results, they are divided into normal and abnormal monitoring points. Repeat this step until all monitoring points of the uplift pressure have completed the anomaly identification.

(3) Monitoring points are divided into two major types according to quantity and spatial distribution. One is individual or discontinuous distribution points, and another is multiple and continuous distribution points.

(4) If an individual monitoring point is diagnosed as abnormal, or the spatial distribution of the abnormal monitoring point is not continuous, operating personnel should focus on checking whether the corresponding monitoring equipment is operating normally. Based on the inspection results, operating personnel determine whether to carry out the structural diagnosis of the concrete dam.

(5) If multiple monitoring points are diagnosed as abnormal, and the spatial distribution of the abnormal monitoring points is relatively continuous, operating personnel should focus on the changes in the structural behavior. The structural diagnosis is carried out for the concrete dam under abnormal uplift pressure.

(6) According to the above analysis, we can clarify the abnormal conditions of uplift pressure and its influence on the structural behavior, which can guide the later operation, management, and maintenance of the concrete dam.

\section{Measured Uplift Pressure Application Method and Software Development}

For most concrete dams, when the abnormal uplift pressure is identified, the causes of the abnormality should be identified as soon as possible. Meanwhile, the reservoir water level should be reduced, and corresponding measures should be taken to eliminate hidden 
dangers in time. However, due to essential tasks of reservoirs, such as flood control, water supply, power generation, and irrigation, some reservoirs cannot be stopped immediately and thoroughly. Therefore, the scope and extent of the abnormal uplift pressure should be clarified as soon as possible, and the safety of concrete dams should be evaluated accurately and reasonably. Then, a more comprehensive and personalized treatment plan is advised, which is of great significance to ensure the project's safety and maximize the social benefits. This research will adopt the FEM to analyze the concrete dam under the measured uplift pressure, and the degree and scope of the influence of abnormal uplift pressure on the stress and displacement of the dam body are clarified.

Before the FEM calculation, it is necessary to clarify the method of applying the uplift pressure. However, there is still no unified understanding of applying the lifting pressure in the FEM [17]. Table 1 shows the four mainstream methods of applying uplift pressure:

Table 1. Main methods of applying uplift pressure in FEM simulation.

\begin{tabular}{|c|c|c|}
\hline Application Method & Assumption & Problems \\
\hline Face force & $\begin{array}{l}\text { Compared with the rock foundation with cracks and } \\
\text { joints, the permeability coefficient of concrete is several } \\
\text { small orders of magnitude. So the seepage pressure not } \\
\text { far from the concrete facing water surface will quickly } \\
\text { decay. The uplift pressure is mainly concentrated on the } \\
\text { concrete surface [38]. }\end{array}$ & $\begin{array}{l}\text { There is a gap between the assumption } \\
\text { that the concrete permeability coefficient } \\
\text { is minimal and the actual situation. }\end{array}$ \\
\hline Body force & $\begin{array}{l}\text { The concrete and rock mass are both water-permeable } \\
\text { materials. After the formation of stable seepage, the } \\
\text { infiltration line of the gravity dam body adopts the } \\
\text { uplift pressure distribution curve. The uplift pressure is } \\
\text { applied by using the submerged unit weight of the } \\
\text { concrete below the infiltration line [2]. }\end{array}$ & $\begin{array}{l}\text { The treatment with different unit weight } \\
\text { lacks a theoretical, which is not } \\
\text { applicable to arch dams [38]. }\end{array}$ \\
\hline Seepage field & $\begin{array}{l}\text { The seepage field of the foundation is obtained in } \\
\text { advance, so the uplift pressure on the foundation } \\
\text { surface can be calculated to apply to the dam calculation } \\
\text { model [39]. The denser the distribution of equal } \\
\text { headlines on the impervious curtain and sliding surface, } \\
\text { the greater the seepage pressure [40]. }\end{array}$ & $\begin{array}{l}\text { The seepage field of the foundation-dam } \\
\text { should be calculated separately. }\end{array}$ \\
\hline Fluid-solid coupling & $\begin{array}{l}\text { Through clarifying the interaction mechanism between } \\
\text { seepage and stress field, the impervious curtain studies } \\
\text { the fluid-solid coupling mechanism of the } \\
\text { foundation-dam [41]. Through the FEM, the stress field, } \\
\text { displacement field [42], and seepage field [43] of the } \\
\text { foundation-dam can be obtained simultaneously. }\end{array}$ & $\begin{array}{c}\text { Multi-field coupling calculation has a } \\
\text { large workload and complex } \\
\text { mechanism [44]. }\end{array}$ \\
\hline
\end{tabular}

In a word, it can be seen that uplift pressure is applied by surface force if the dam body is regarded as impervious material. The uplift pressure is applied by physical force if the dam body is regarded as pervious material. Compared with the physical force, applying uplift pressure in face force form will produce more significant tensile stress at the dam heel, according to the previous calculation and analysis results [45]. Thus, the analysis of the structural behavior of concrete dams is partially safe with the face force application method [46]. At the same time, the measured uplift pressure data accurately reflects the uplift pressure on the dam foundation surface, but it cannot reflect the overall seepage field on the dam body and dam foundation. Therefore, the surface force application method is used in this study, the measured value and distribution of uplift pressure can be applied to the foundation surface.

Due to the influence of topography, the profile and thickness of the dam foundation at different elevations of concrete dams are different. A limited number of monitoring points cannot fully reflect the uplift pressure in the dam foundation with complex shape, so the FEM cannot complete directly only using the measured uplift pressure data. Hence, an application method of measured uplift pressure is proposed. Though fitting the foundation 
curve, positioning integration points, and numerical interpolation, a limited number of measured uplift pressure are converted into uplift pressure values of each element in the dam foundation. Through this method, the rapid conversion from original monitoring data to numerical simulation boundary conditions is realized. The structural behavior of the concrete dam, under design and measured uplift pressure, can be analyzed accurately and quickly. The flow chart of the application method of measured uplift pressure is shown in Figure 3.

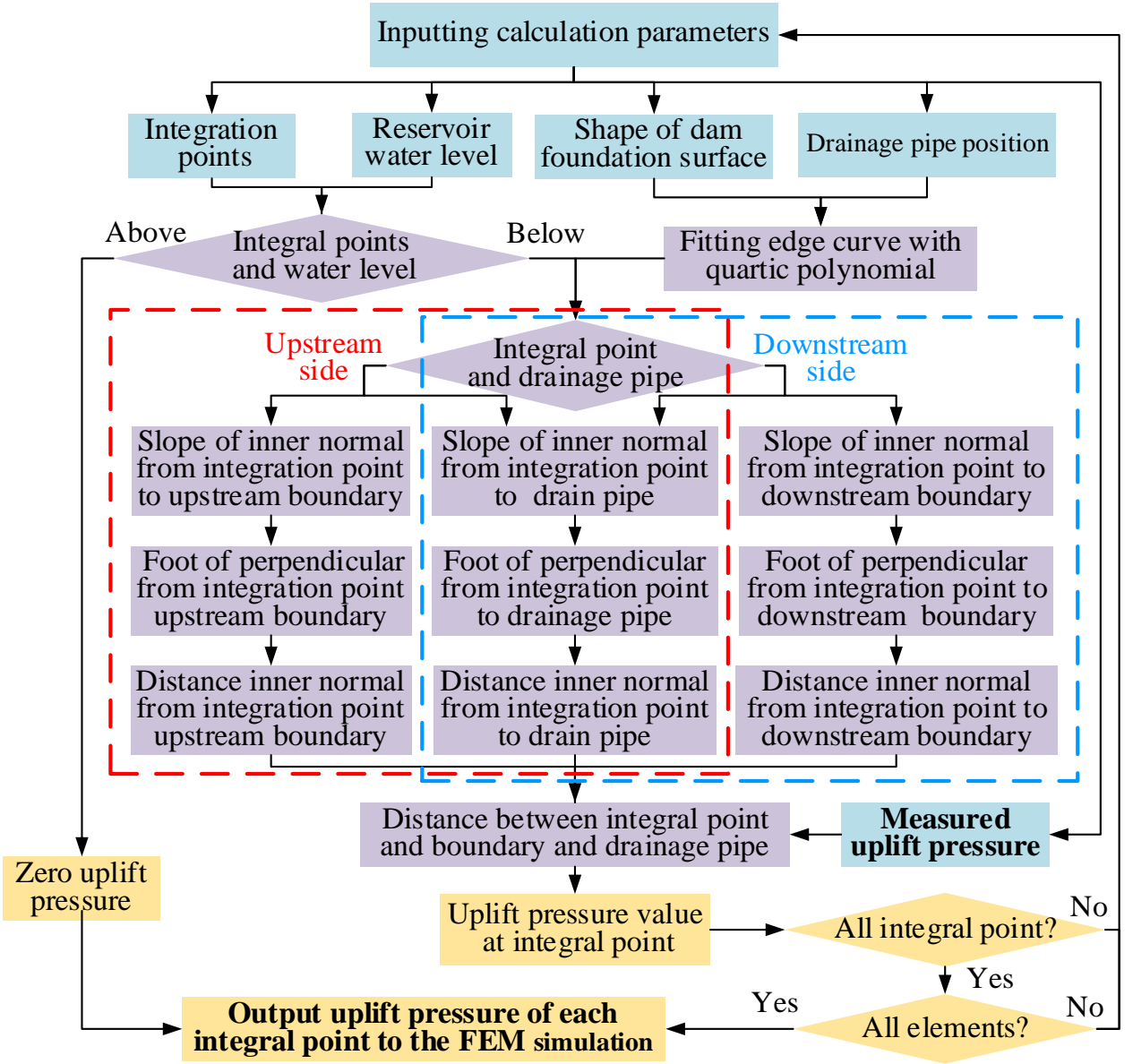

Figure 3. Flow chart of the application method of measured uplift pressure.

According to Figure 3, the calculation steps of the application method of measured uplift pressure are as follows:

(1) All kinds of essential data are inputted, including the upstream water level, the shape, and elevation of dam foundation surface, the coordinate of drainage pipe, the coordinate of integration points of foundation surface in finite element model, and other necessary data.

(2) Influenced by the actual topography, the foundation surface's boundary and the drainage pipe's position line, formed by the intersection of the dam body and dam foundation, are irregular. To facilitate the positioning calculation of integration points, it is necessary to construct the fitting curve equation of the boundary and the position. Through different projects, the quartic polynomial shows a better-fit effect to meet the needs of subsequent calculation.

(3) Selecting an integration point of an element in the FEM model, the relationship between the integration point and the water level is judged. If this integration point is below the water level, the following calculation step is to proceed. Otherwise, the uplift force of this integration point is set equal to zero. 
(4) The positional relationship between the integration point and the drainage pipe is judged and divided into the upstream and the downstream integration point. Then, to determine the position of the integration point in the cross-section, the inner normal between the integration point and the foundation boundary is searched, of which the slope, distance, and foot of a perpendicular are calculated. The same operation should carry out for the integration point and the drainage pipe curve.

(5) According to the measured uplift pressure and the position of the integration point in the cross-section, the uplift pressure at the integration point is calculated by interpolation.

(6) The applying method judges whether all the current element's integration points have finished the uplift pressure calculation. If not, steps (2) to (5) are repeated.

(7) The applying method judges whether all FEM elements on the foundation surface have completed uplift pressure calculation. If not, steps (2) to (6) are repeated.

(8) According to the interface requirements of the FEM, the measured uplift pressure of each integration point is output. The uplift pressure is called when the FEM simulation is carried out.

According to the above analysis, it can be seen that the application method of measured uplift pressure includes a lot of data conversion, data fitting, loop computation, judgment computation, and calculation. Thus, the manual calculation is time-consuming and prone to errors. To facilitate the popularization and application of this applying method, researchers and designers can quickly complete the application of the measured uplift pressure. The visual application program of uplift pressure of concrete dam is compiled into the software. The operation interface is shown in Figure 4. The software interface includes the shortcut operation command area, parameter setting area, operation area, calculation process display area, results index area, and data visualization area, enabling users to complete the uplift pressure application quickly.

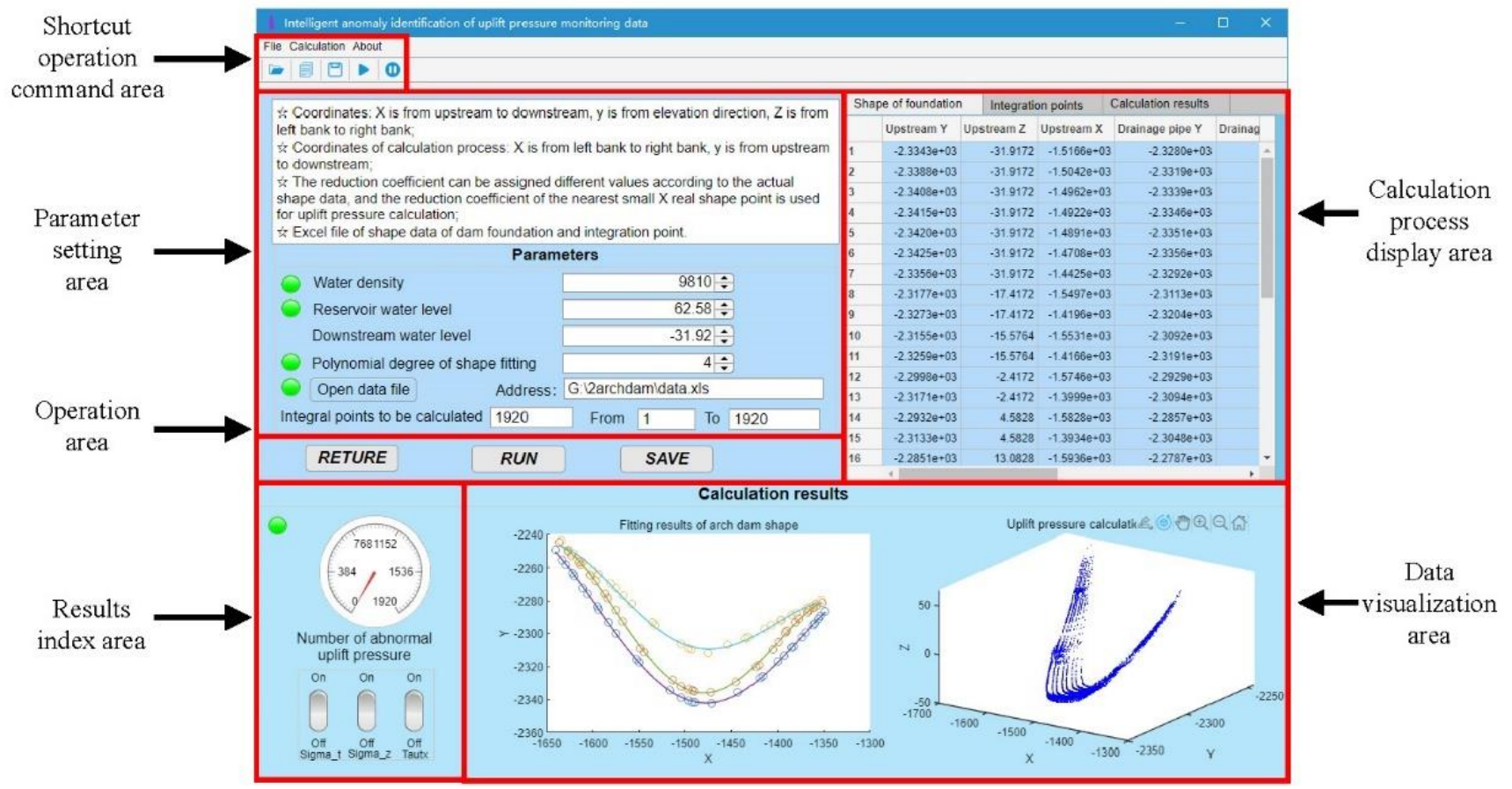

Figure 4. Software interface of the application method of measured uplift pressure.

In the numerical simulation of a concrete dam, the uplift pressure is an indispensable load for a gravity dam; the uplift load should be considered in the design of a gravity arch dam and medium-thick arch dam. For thin arch dams, uplift pressure accounts for a small proportion of the total load because of the small area of the dam foundation, which can be 
neglected in the design process. As for the distribution of uplift pressure, it is generally considered that uplift pressure will decrease after impervious curtain and drainage pipe, and the drainage pipe is assumed as the reduction point. According to the experience of many concrete dams in China, it is considered that the reduction coefficient at the drainage pipe in the riverbed should be less than $0.2-0.3$.

\section{Case Study}

\subsection{Project Overview}

A reservoir is located at the edge of the mountain range, with a controlled drainage area of $362 \mathrm{~km}^{2}$. The reservoir area is a canyon topography, showing a Y shape. The satellite map, contour map, and topographic map of the reservoir are shown in Figure $5 \mathrm{a}-\mathrm{c}$. The reservoir is responsible for the water supply to nearby cities, with an average annual water supply of 72.3 million $\mathrm{m}^{3}$. The water retaining structure is a roller compacted concrete arch dam with double-curvature, of which the dam height is $98.5 \mathrm{~m}$. The $12 \mathrm{~m}$-wide crest outlet is located in the middle of the dam, and the bottom outlet is arranged on the left and below of the crest outlet. To analyze the structural safety state of the concrete arch dam, a 3D FEM model considering the transverse joints, inducing joints, monitoring points, and weak strength surface on the foundation is established, as shown in Figure 5d.

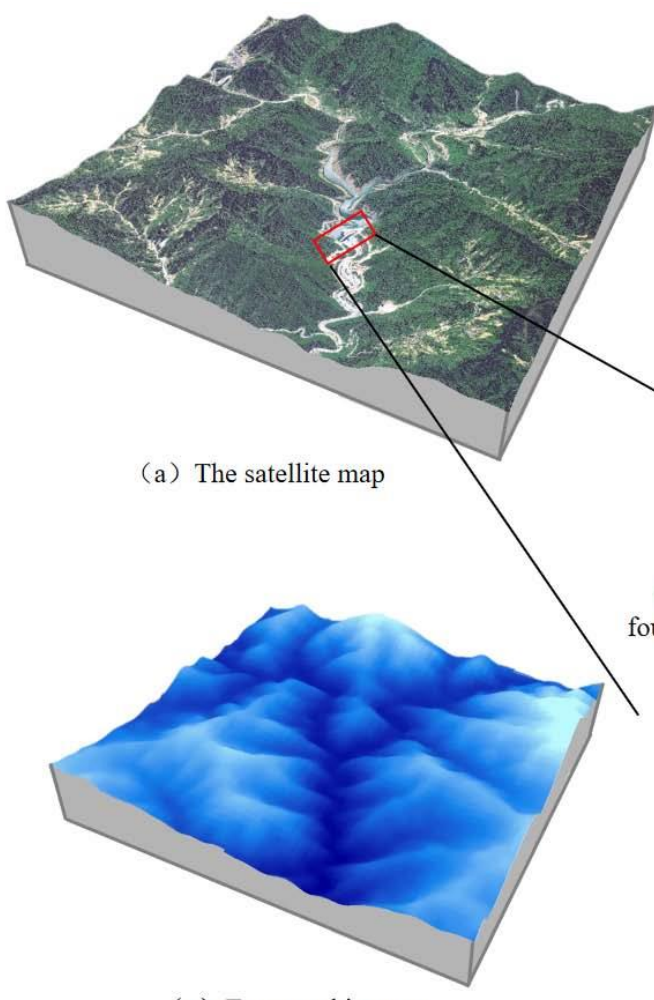

(c) Topographic map

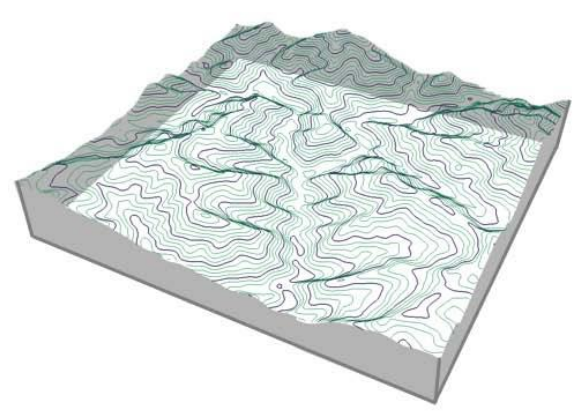

(b) Contour map

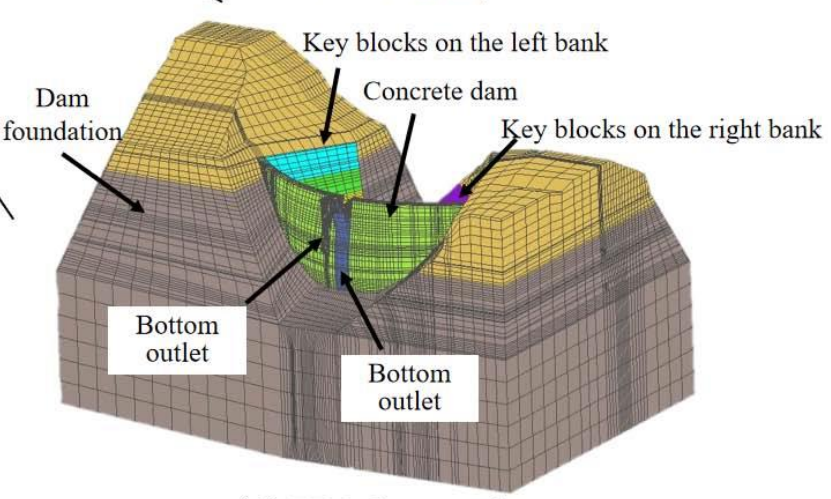

(d) FEM of concrete dam

Figure 5. Location of the concrete arch dam and its FEM model.

The FEM model includes the concrete arch dam body and the left and right abutment mountains. Its foundation extends for $150 \mathrm{~m}$ to the upstream, downstream, both banks, and the bottom of the dam foundation, respectively. The model adopts eight-node hexahedron elements, with 14,590 elements for dam body, 8365 corresponding nodes, 102,938 elements for foundation and 1,191,543 corresponding nodes. A fixed constraint is imposed on the bottom of the model, and a normal constraint is imposed on the periphery of the model. The main loading conditions include self-weight, water load, uplift pressure, temperature load, and sediment pressure in the calculation process. The water load is applied to the upstream face of the dam and the reservoir area by face force. In addition, contact elements 
are set between the blocks in the dam abutment and the mountains. ABAQUS software is used for this numerical simulation. Material properties of the dam and foundation are shown in Table 2.

Table 2. Material properties of the dam and foundation.

\begin{tabular}{lcccc}
\hline & Density $\left(\mathbf{k N / \mathbf { m } ^ { 3 } )}\right.$ & $\begin{array}{c}\text { Modulus of Elasticity } \\
(\mathbf{G P a})\end{array}$ & $\begin{array}{c}\text { Poisson } \\
\text { Ratio }\end{array}$ & $\begin{array}{c}\text { Coefficient of Linear } \\
\text { Extensibility }\left(/{ }^{\circ} \mathbf{C}\right)\end{array}$ \\
\hline Dam concrete & 24 & 20 & 0.167 & $0.83 \times 10^{-5}$ \\
Foundation above 865 m elevation & 27 & 10 & 0.27 & $1 \times 10^{-5}$ \\
Foundation below 865 m elevation & 27 & 15 & 0.21 & $1 \times 10^{-5}$ \\
\hline
\end{tabular}

To master the change of uplift pressure in the dam foundation, a vertical section and three cross-sections are laid out at the dam foundation using vibrating wire osmometers. The vertical section of the uplift pressure monitoring points is arranged between the curtain grouting and drainage pipe in the dam foundation. There are 13 osmometers (P1-P13) arranged in the vertical section, which can directly observe the reduction of uplift pressure behind the curtain. The $2 \#$ cross section, in the left quarter arch of the dam, has 3 osmometers (P1-1-P1-3), P2-1-P2-3 in 3\# cross section in the arch crown, and P3-1-P3-3 in $4 \#$ cross section in the right quarter arch. The data collection method is automatic acquisition and monitoring. The layout of uplift pressure monitoring points in this concrete arch dam is shown in Figure 6.

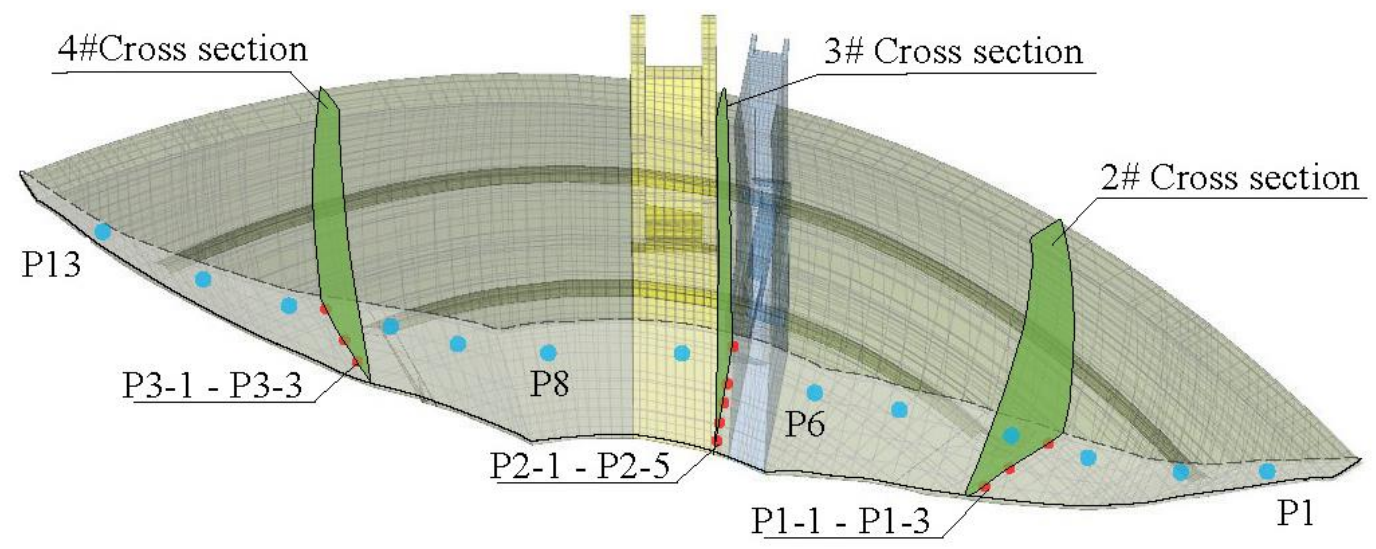

Figure 6. Layout of uplift pressure monitoring points in concrete arch dam.

\subsection{Anomaly Identification of Uplift Pressure}

Firstly, the measured uplift pressure and the reservoir water level are normalized from -1 to 1 , and all monitoring points of uplift pressure are identified using the anomaly identification model based on DBSCAN. This model identity that the P2-2 point has been abnormal since March 2016, and several uplift pressure monitoring points have been abnormal since 7 October 2017. These abnormal monitoring points include P2-2, P2-3, P2-4, and P2-5 in Section 3\# as well as P6, P7, and P8 in the vertical section. The other measuring points are normal.

Taking the P2-3 monitoring point as an example, the anomaly identification results of the uplift pressure based on the DBSCAN model are shown in Figure 7. Additionally, 6 abnormal occurrence points (noise points) from 7 October 2017 to 14 October 2017 and 4 abnormal occurrence points from 15 September 2019 to 19 September 2019 are identified by the DBSCAN model. At the same time, the new cluster \#5 - cluster \#12 after the abnormal occurrence points are identified as abnormal stabilization values of uplift pressure. According to its P2-3 measuring process line, the abnormal occurrence points approximate corresponds to the initial stage of the abnormal process, and cluster \#5 - cluster 
\#12 approximate corresponds to the stable stage of the abnormal process. The anomaly identification results of other monitoring points are similar to those of P2-3.

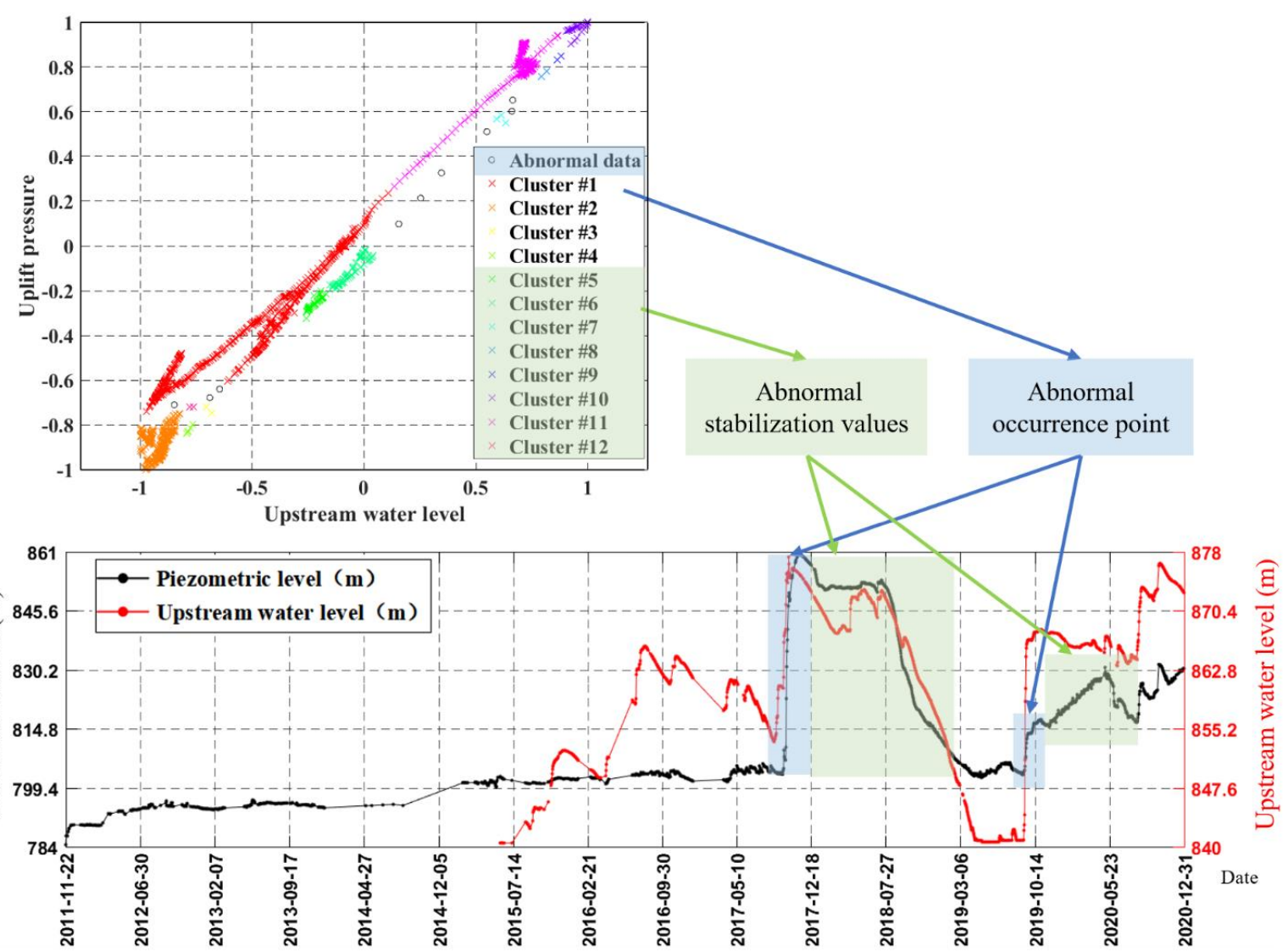

Figure 7. Anomaly identification result of uplift pressure at the P2-3 monitoring point.

At the same time, based on the monitoring data of the P2-3 measuring point and the upstream water level, local outlier factor and K-means are used to identify the anomaly of uplift pressure monitoring data to compare with the DBSCAN. The identification results of K-means are different from the actual uplift pressure anomaly, mainly because the distribution distance between abnormal measured values and normal measured values is close, so the clustering method based on distance alone cannot identify the occurrence of abnormal uplift pressure. Otherwise, six abnormal uplift pressures were identified by the local outlier factor, which is less than all abnormal uplift pressure monitoring data. Therefore, the application effect of the anomaly identification model of uplift pressure, based on DBSCAN, a Density-based clustering method, is good, identifying the abnormal occurrence point and abnormal stabilization values. In addition, from the P2-3 measuring curve, it can be seen that abnormal uplift pressure usually corresponds to the rapid growth period of reservoir water level, so it is preliminarily speculated that the rapid growth of reservoir water level is the main reason for abnormal uplift pressure.

To verify the accuracy of the anomaly identification result of the DBSCAN, the variation of the annual maximum reduction coefficient of uplift pressure monitoring points in $3 \#$ cross section and vertical section is statistically analyzed, as shown in Figure 8. It can be seen that: (1) P2-1 point is located on the upstream side of the grouting curtain. Thus, the measured value of the P2-1 point is approximately equal to the reservoir water level, and the reduction factor is close to 1.0. (2) P2-2 point is located at the downstream side of the grouting curtain. The smallest reduction factor of the P2-2 point was 0.30 in 2015, and the reduction coefficient is more significant and above 0.80 after 2016 . The reduction factor of the P2-2 point exceeds the expected value for a long time, indicating that the grouting 
curtain nearby the P2-2 point may be destroyed. (3) The P2-3, P2-4, and P2-5 points are located on the downstream side of the grouting curtain, and their reduction coefficients have increased and shown abnormal operation since 2017. (4) The reduction coefficient of P6, P7, and P8 points meet the expectation in 2015-2016 and increase significantly in 2017 -2020. (5) The reduction coefficient of other uplift pressure points in the vertical section is stable at $0.2-0.3$, which accords with the experience. Through the annual maximum reduction coefficient analysis, the anomaly analysis results are consistent with those of the anomaly identification model. The accuracy of anomaly identification of the DBSCAN is verified. It is concluded that the anomaly uplift pressure occurred locally in 2016 and developed in 2017, mainly in the dam section of the riverbed.

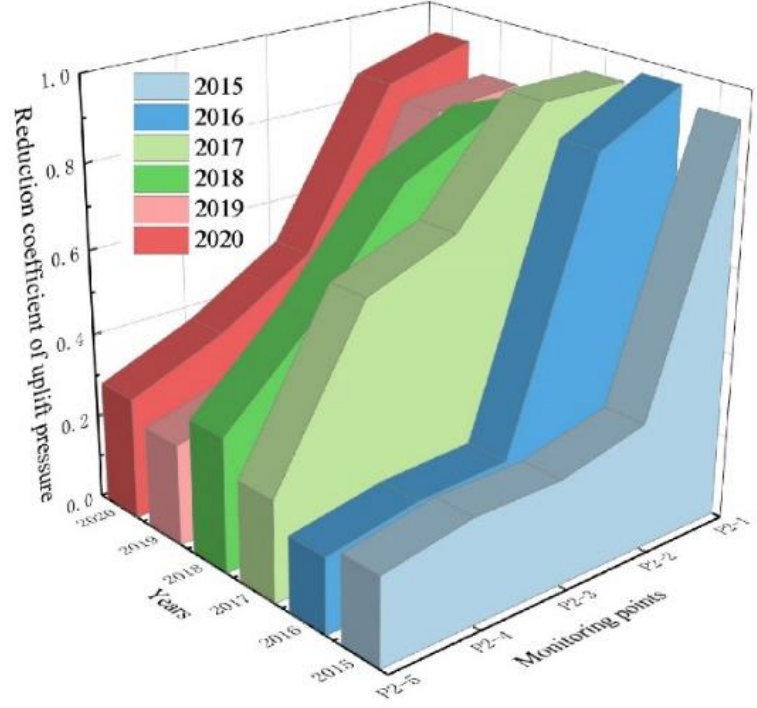

(a) P2-1-P2-5 of 3 \# cross section

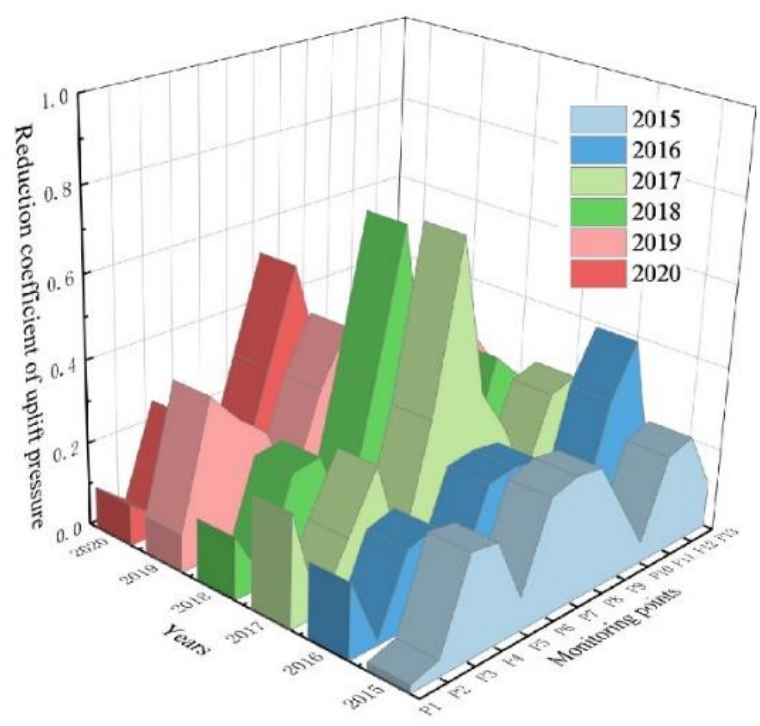

(b) P1-P13 of vertical section

Figure 8. Variation of annual maximum reduction coefficient of uplift pressure monitoring points.

To further verify the accuracy of the anomaly identification result of the DBSCAN, SIR-4000 geological radar and $100 \mathrm{MHz}$ shielding detection antenna are used for nondestructive testing. Non-destructive testing of the dam foundation in the middle of the riverbed is carried out in the corridor at the bottom of the dam body, and the testing result is shown in Figure 9. At a depth of 7-15 m near the P2-4 monitoring point, the overall continuity of the foundation is relatively poor, and the in-phase axis dislocation is intense. There are apparent small-scale wave groups, and the local reflection wave appears as an arc. The high frequency has a specific loss, and the low frequency is locally prominent. It is speculated that the geological body here is not dense, and there may be cracks. Therefore, the non-destructive testing results further verify the possibility of seepage failure in the riverbed and the accuracy of anomaly identification model based on the DBSCAN. 


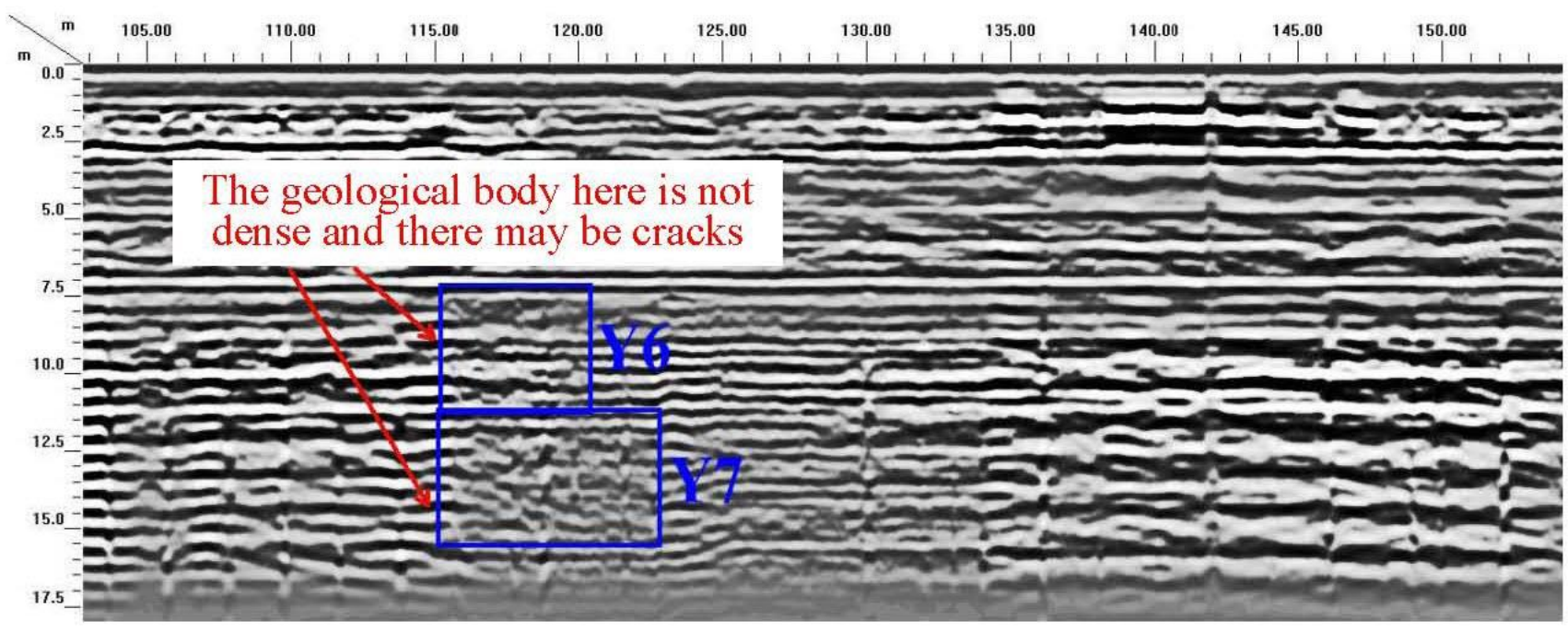

Figure 9. Non-destructive testing result of dam foundation.

\subsection{Abnormal Uplift Pressure Applied in the FEM Model}

To analyze the safety state of the concrete arch dam in the worst case, the measured uplift pressure, under a high water level, is selected as the load applied in the FEM model of the arch dam. Therefore, the recent high reservoir water level of $876.51 \mathrm{~m}$ on 20 October 2020 , is selected. The measured uplift pressure of the $3 \#$ cross section and vertical section is shown in Figure 10, and the other measured uplift pressure is approaching normal.

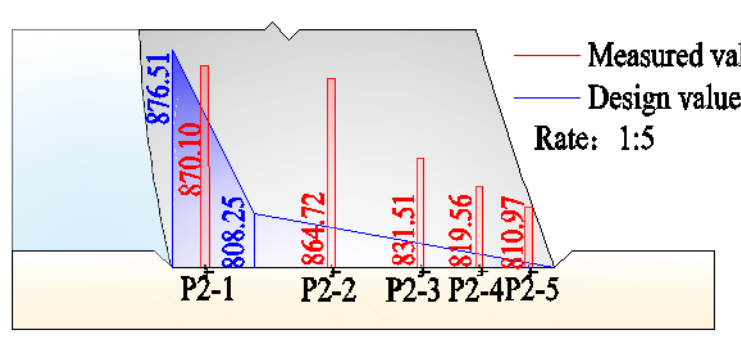

(a) 3\# Cross section

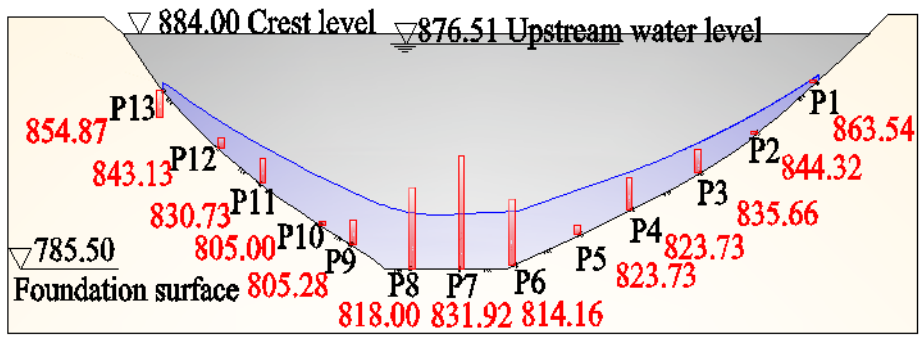

(b) Vertical section

Figure 10. Measured uplift pressure under the high reservoir water level.

It can be seen, from Figure 10a, that the measured uplift pressure of each osmometer at the bottom of the $3 \#$ section has exceeded the empirical value. The measured P6, P7, and P8 points show apparent abnormal phenomena, and the other measured points conform to the empirical uplift pressure distribution law. According to all uplift pressure points, abnormal uplift pressure mainly occurs in the riverbed. The uplift pressure of other dam sections meets the empirical. In the FEM simulation, the larger value of measured uplift pressure and experienced uplift pressure will be selected as uplift pressure load. The measured uplift pressure is adopted for the dam section in the riverbed because it is greater than the empirical uplift pressure. Based on similar considerations, the empirical uplift pressure is adopted for the dam sections on both banks.

Based on the anomaly identification and analysis results of uplift pressure, the appplication method and software proposed in Chapter III are adopted. The measured uplift pressure value is adopted in the middle dam section of the riverbed. Finally, the design and measured value and distribution of uplift pressure in the dam foundation are shown in Figure 11. Under the measured uplift pressure, the uplift pressure after the grouting curtain is obviously increased. Thus, this application method can better reflect the spatial distribution and abnormal position of uplift pressure. 


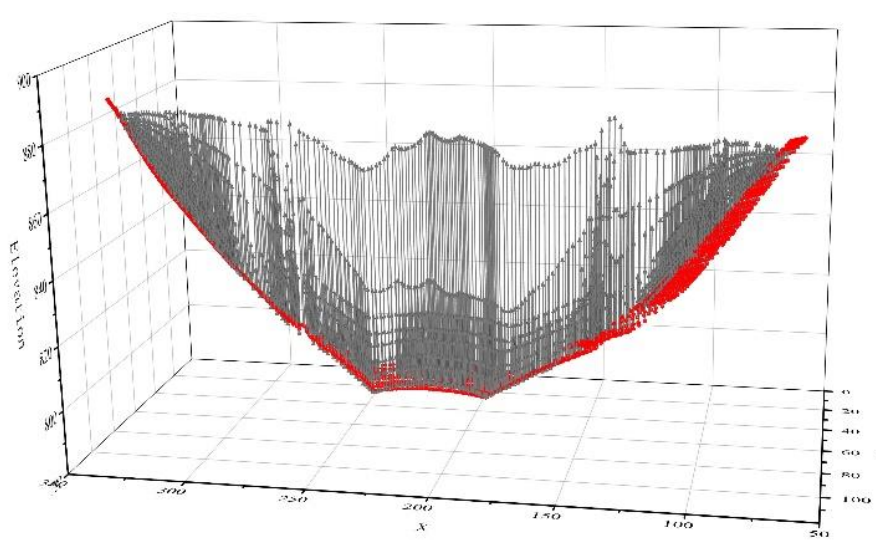

(a) Design uplift pressure

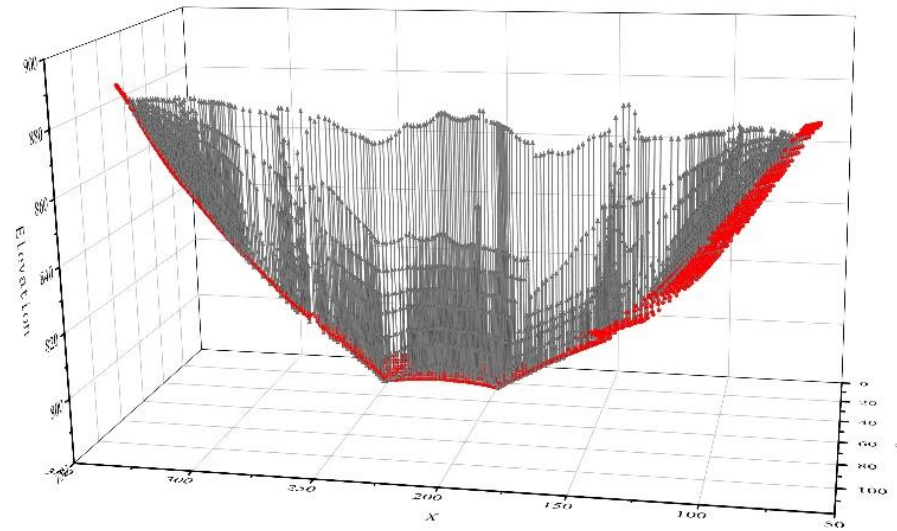

(b) Measured uplift pressure

Figure 11. Distribution of design and measured uplift pressure.

\subsection{Structural Diagnosis of the Arch Dam under Abnormal Uplift Pressure}

Generally, during the operation period, if the uplift pressure of this concrete arch dam exceeds the experience expectation, the seepage control effect of the dam may be poor. This reservoir is responsible for the water supply of nearby cities, and it can't stop operation wholly and immediately. Thus, it is necessary to clarify the safety state of this dam under abnormal uplift pressure as soon as possible, as well as provide advice for the operation. Applying the measured uplift, the stress and deformation of this arch dam are rechecked to clarify the influence of the abnormal measured uplift pressure.

\section{(1) Stress analysis of arch dam}

The stress analysis of the concrete arch dam is analyzed under the unfavorable condition of normal water level and temperature drop in this paper. The stress of dam and foundation in the riverbed, under design and measured uplift pressure, is shown in Table 3. The stress distribution is shown in Figure 12, in which the tensile stress is positive and the compressive stress is negative. It can be seen from Table 3 and Figure 12 that the stress changes are as follows: compared with the design uplift pressure, the maximum tensile stress of the dam body decreased from $8.44 \mathrm{MPa}$ to $8.37 \mathrm{MPa}$ under the measured uplift load, which appeared at the dam shoulder. The maximum compressive stress of the dam body decreased from $9.10 \mathrm{MPa}$ to $9.05 \mathrm{MPa}$, which appeared at the foundation in the riverbed. Under the action of designed and measured uplift pressure, the stress distribution regularity of the dam body is very similar.

Table 3. Stress under design and measured uplift pressure (Unit: MPa).

\begin{tabular}{clcccc}
\hline & & \multicolumn{2}{c}{ Major Principal Stress } & \multicolumn{2}{c}{ Minor Principal Stress } \\
& & Dam & Foundation in Riverbed & Dam & Foundation in Riverbed \\
\hline Design uplift & Maximum & 8.44 & 2.73 & 0.70 & 0.11 \\
pressure & Minimum & -1.51 & -0.82 & -9.10 & -6.06 \\
Measured uplift & Maximum & 8.37 & 2.90 & 0.69 & 0.13 \\
pressure & Minimum & -1.50 & -0.81 & -9.05 & -5.97 \\
\hline
\end{tabular}




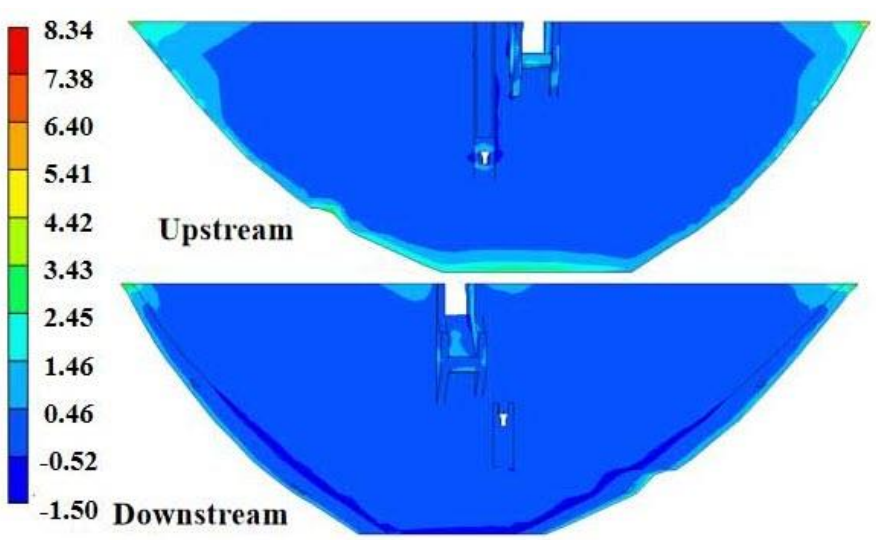

(a) Major principal stress

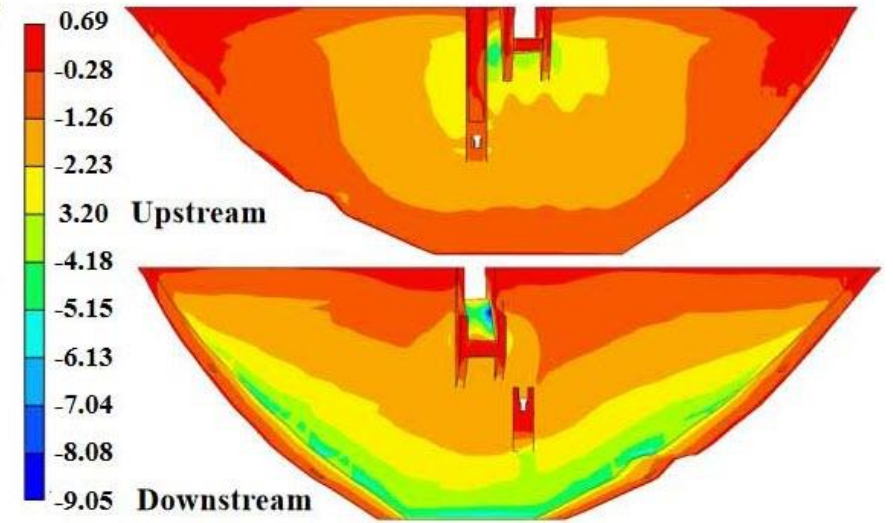

(b) Minor principal stress

Figure 12. Contour map of dam stress under measured uplift pressure (Unit: MPa).

The foundation in the riverbed is the most obviously affected structural part. Table 3 and Figure 13 present that the maximum tensile stress in the foundation of the riverbed increased from $2.73 \mathrm{MPa}$ to $2.90 \mathrm{MPa}$, which appeared upstream of the dam foundation. The maximum compressive stress decreased from 6.06 $\mathrm{MPa}$ to $5.97 \mathrm{MPa}$, which appeared on the downstream face of the dam foundation. Under the designed and measured uplift pressure, the stress distribution regularity in the foundation of the riverbed is very similar, and the stress range changes slightly. With the increase of uplift pressure, the stress values in the foundation of the riverbed increase, which means the tensile stress increases, and the compressive stress decreases.

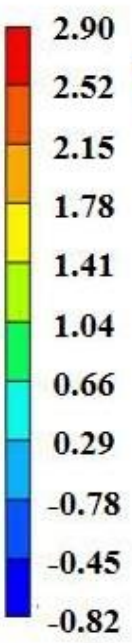

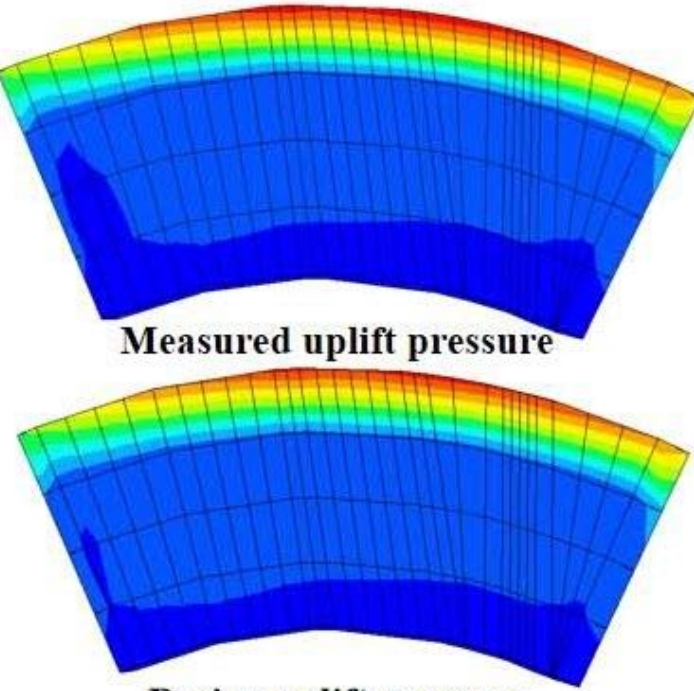

Design uplift pressure

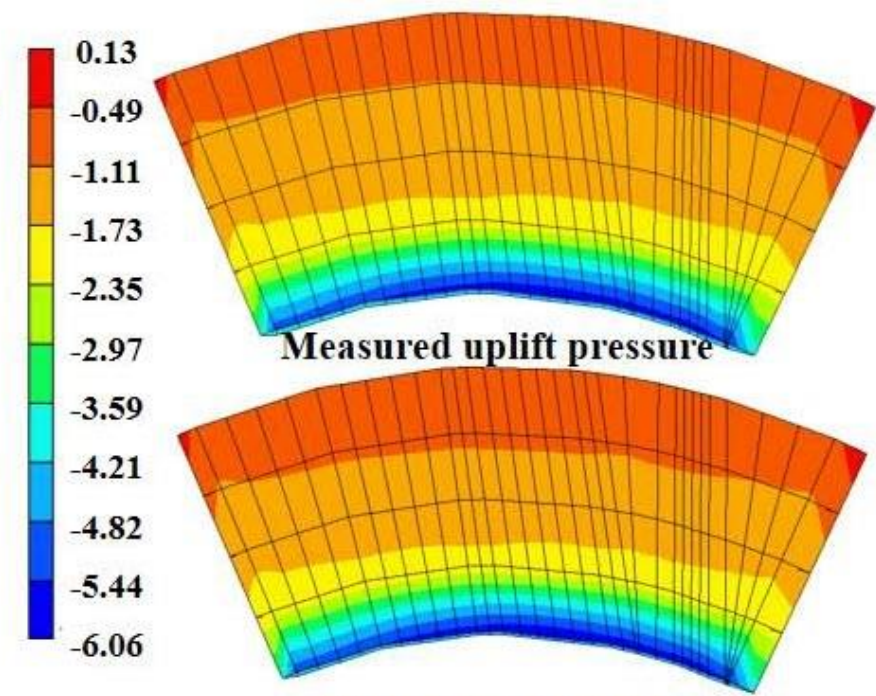

Design uplift pressure

(a) Major principal stress

(b) Minor principal stress

Figure 13. Contour map of foundation stress in the riverbed under measured uplift pressure (Unit: MPa).

The abovementioned major and minor principal stress are too large due to the local stress concentration phenomenon in FEM. The calculation results of FEM are usually converted into equivalent stress as a criterion in engineering design. A group of elements of the foundation surface of each dam section is selected to calculate equivalent stress in this paper. The equivalent stress of upstream and downstream faces of the dam foundation is shown in Figure 14. Under the design uplift pressure, the maximum equivalent tensile 
stress of the dam foundation is $1.07 \mathrm{MPa}$, which occurs at the dam shoulder. The maximum equivalent compressive stress is $3.04 \mathrm{MPa}$, which occurs at the foundation of the riverbed. Under the measured uplift pressure, the maximum equivalent tensile stress of dam foundation is $1.17 \mathrm{MPa}$, and the maximum equivalent compressive stress is $3.90 \mathrm{MPa}$, in the same position. According to the Chinese design standard, with the corresponding load and concrete type, the equivalent tensile stress should not be greater than $1.5 \mathrm{MPa}$, and the equivalent compressive stress should not be greater than $5.71 \mathrm{MPa}$. Therefore, the equivalent tensile and compressive stress of the concrete arch dam, under the measured uplift pressure, still meets the standard requirements at present. With comparative design and measured uplift pressure, the equivalent stress at the foundation surface changes most obviously in the riverbed. Under the measured uplift pressure, the equivalent stress in the riverbed shows the obvious abrupt change.

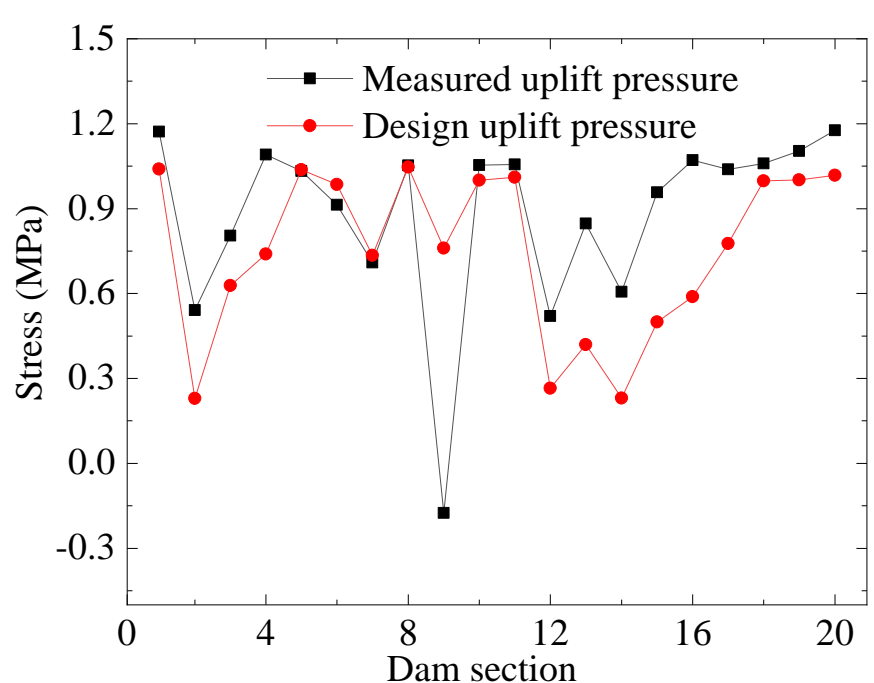

(a) Maximum principal stress on the upstream surface

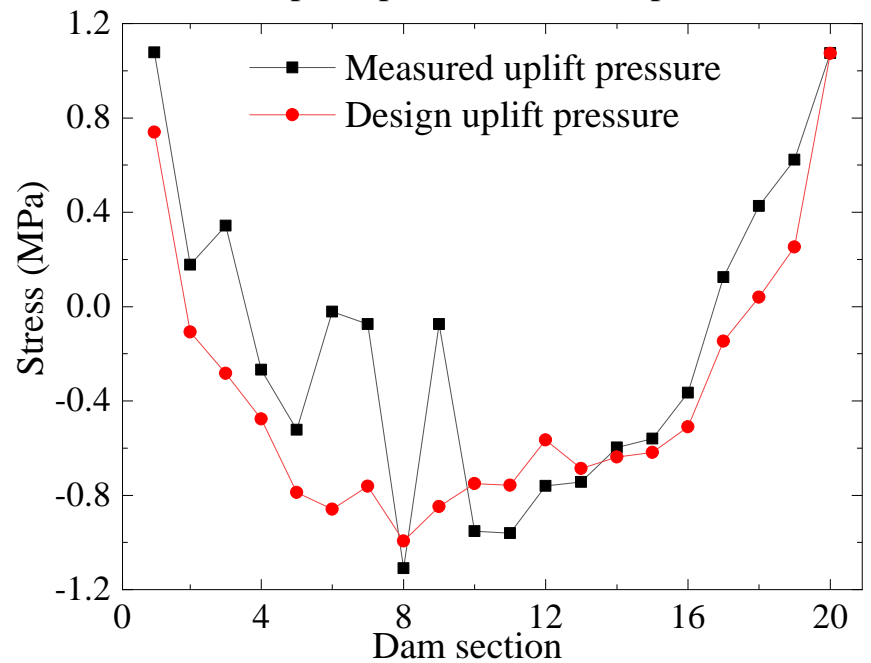

(c) Maximum principal stress on downstream surface

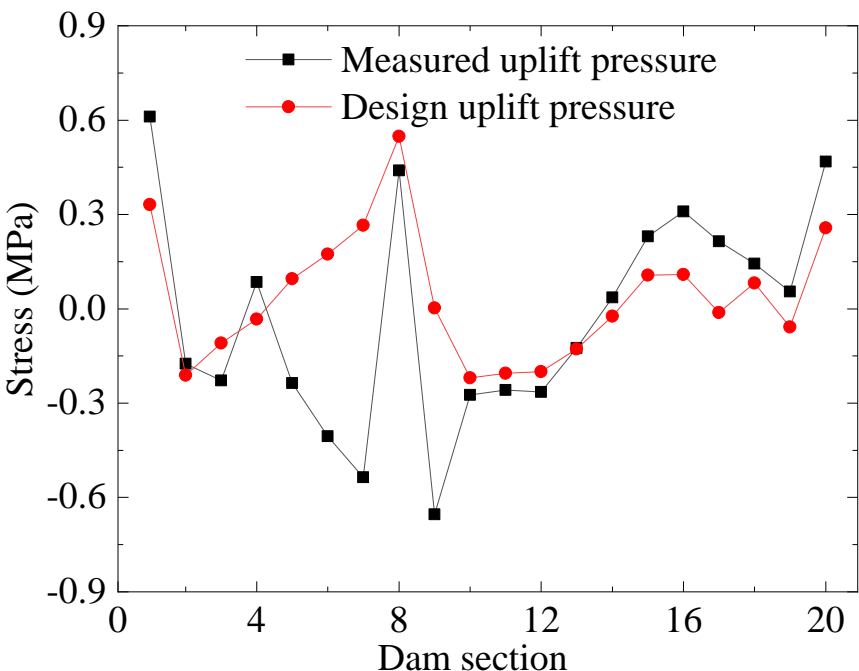

(b) Minimum principal stress on upstream surface

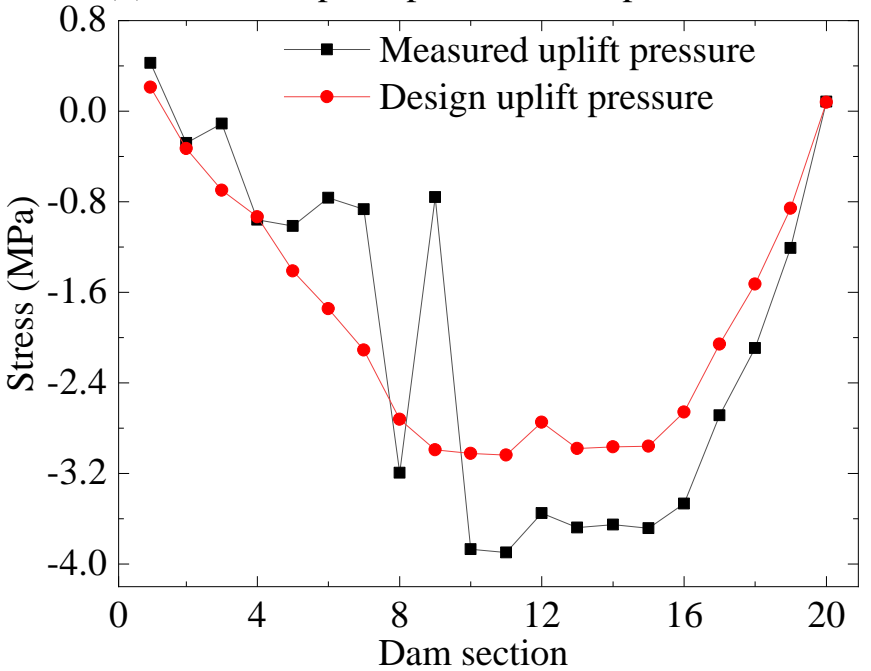

(d) Minimum principal stress on downstream surface

Figure 14. Comparison of equivalent stress of dam foundation under design and measured uplift pressure.

The research has also shown that the compressive stress, at the foundation of the riverbed, decreases with the measured uplift pressure increases, which is not conducive to the long-term safety and stability of the arch dam. At present, under the action of measured uplift pressure, the equivalent tensile and compressive stress values of the concrete arch 
dam still meet the standard requirements, which indicates that the structural strength of the concrete arch dam is relatively high.

(2) Deformation analysis of arch dam

The displacement of the concrete arch dam is analyzed under the same working condition of the stress analysis. The displacement changes of the dam and the foundation in the riverbed are shown in Table 4, of which distribution is shown in Figure 15. Upward is positive for vertical displacement, the downstream is positive for displacement along the river, and the left to the right bank is positive for transverse displacement. Table 4 and Figure 15 presents that: (1) Compared with the design uplift pressure, the vertical settlement of the dam body is reduced from $1.13 \mathrm{~cm}$ to $1.12 \mathrm{~cm}$ under the measured uplift pressure, appearing at $1 / 3$ height of the dam crest. (2) The downstream displacement of the dam body increased from $3.32 \mathrm{~cm}$ to $3.33 \mathrm{~cm}$, appearing in the middle of the dam crest. (3) The maximum transverse settlement of the dam body decreased from $1.10 \mathrm{~cm}$ to $1.09 \mathrm{~cm}$, appearing at a quarter arch. Transverse displacement from both banks to the riverbed decreased. (4) Under the design and measured uplift pressure, the displacement distribution regularity is highly similar.

Table 4. Displacement under design and measured uplift pressure (m).

\begin{tabular}{cccccccc}
\hline & & Vertical Displacement & \multicolumn{2}{c}{ Displacement along River } & \multicolumn{2}{c}{ Transverse Displacement } \\
& & Dam & $\begin{array}{c}\text { Foundation } \\
\text { in Riverbed }\end{array}$ & Dam & $\begin{array}{c}\text { Foundation } \\
\text { in Riverbed }\end{array}$ & Dam & $\begin{array}{c}\text { Foundation } \\
\text { in Riverbed }\end{array}$ \\
\hline Design uplift & Maximum & $2.28 \times 10^{-3}$ & $-1.27 \times 10^{-4}$ & $3.32 \times 10^{-2}$ & $3.38 \times 10^{-3}$ & $1.10 \times 10^{-2}$ & $7.33 \times 10^{-4}$ \\
pressure & Minimum & $-1.13 \times 10^{-2}$ & $-3.89 \times 10^{-3}$ & $-6.05 \times 10^{-4}$ & $2.08 \times 10^{-3}$ & $-6.17 \times 10^{-3}$ & $-1.70 \times 10^{-4}$ \\
$\begin{array}{c}\text { Measured uplift } \\
\text { pressure }\end{array}$ & Maximum & $2.49 \times 10^{-3}$ & $8.96 \times 10^{-5}$ & $3.33 \times 10^{-2}$ & $3.37 \times 10^{-3}$ & $1.09 \times 10^{-2}$ & $7.08 \times 10^{-4}$ \\
\hline
\end{tabular}

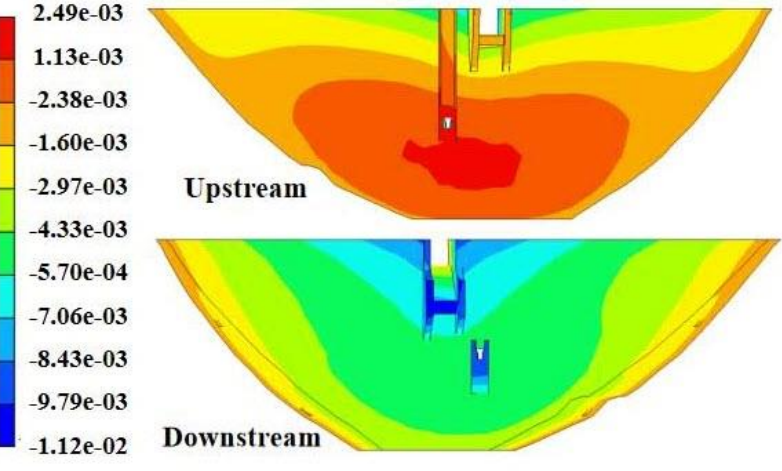

(a) Vertical displacement

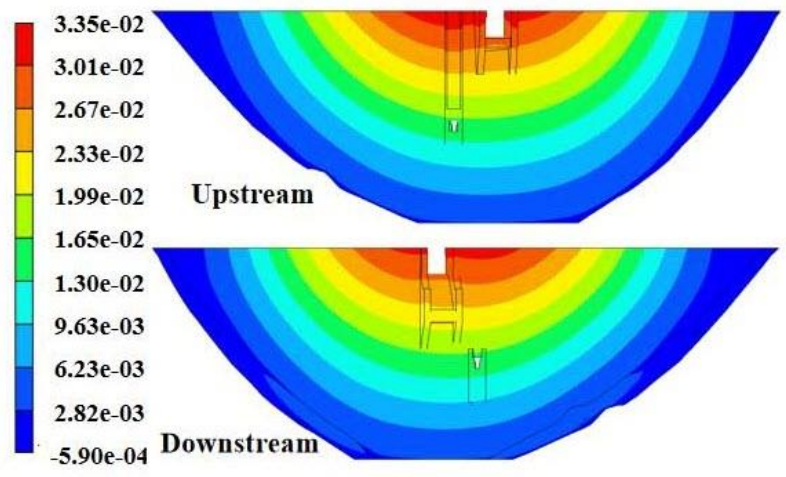

(b) Displacement along river

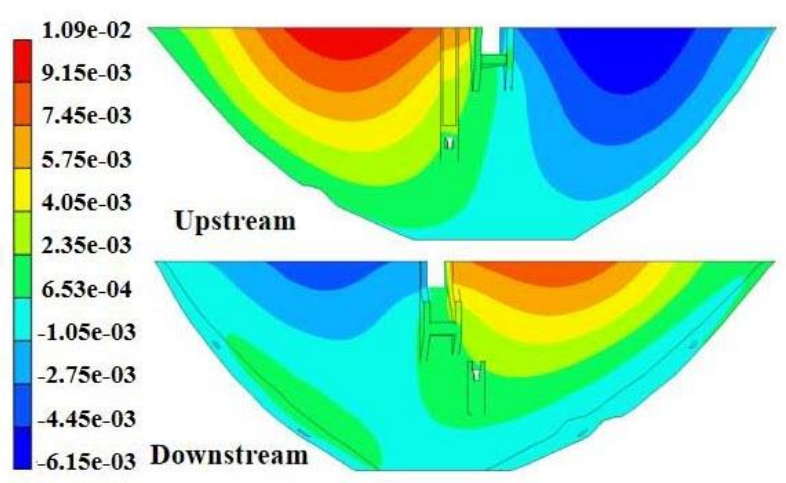

(c) Transverse displacement

Figure 15. Contour map of dam displacement under measured uplift pressure (Unit: m). 
From Table 4 and Figure 16, we can see that: (1) compared with the design uplift pressure, the vertical displacement of the dam body changes from $1.27 \times 10^{-4} \mathrm{~m}$ downward to $8.96 \times 10^{-5} \mathrm{~m}$ upward under the measured uplift pressure, appearing in the upstream surface; (2) the downstream displacement along the river decreased from $3.38 \times 10^{-3} \mathrm{~m}$ to $3.37 \times 10^{-3} \mathrm{~m}$, appearing in the middle of the foundation surface. (3) The maximum transverse settlement of the dam body is from $7.33 \times 10^{-4} \mathrm{~m}$ decreased to $7.08 \times 10^{-4}$ $\mathrm{m}$, appearing in the right bank and downstream side of the foundation. (4) With the increase of uplift pressure, the foundation surface in the riverbed showed an upward tendency in vertical displacement, upstream along the river, moving to the middle in transverse displacement. (5) Under the design and measured uplift pressure, the displacement distribution of the dam is similar.

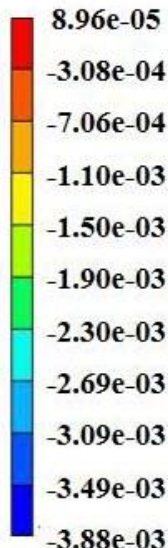

$3.88 \mathrm{e}-03$

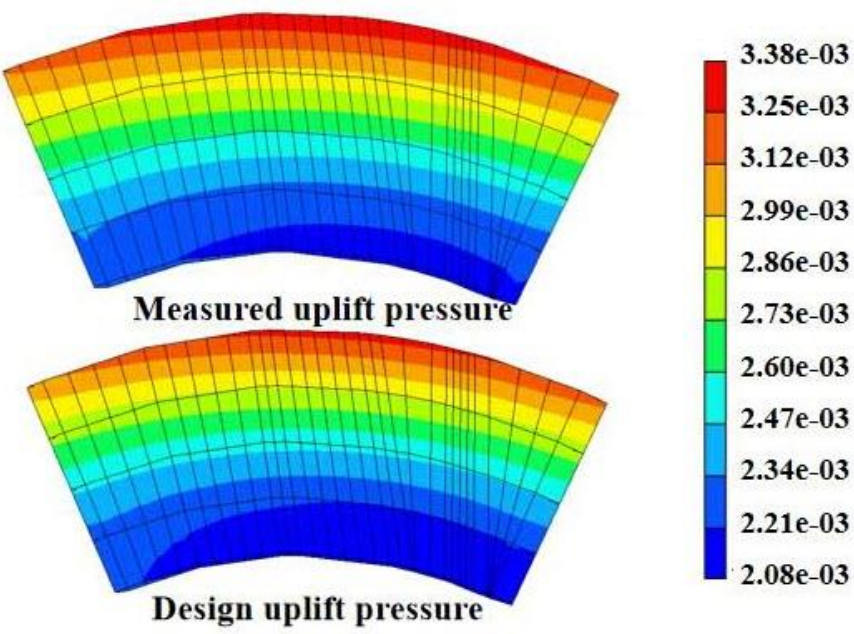

(a) Vertical displacement

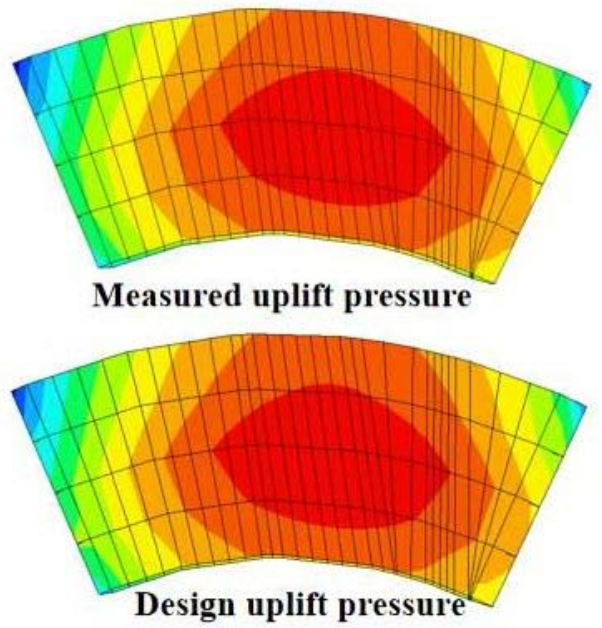

(b) Displacement along river
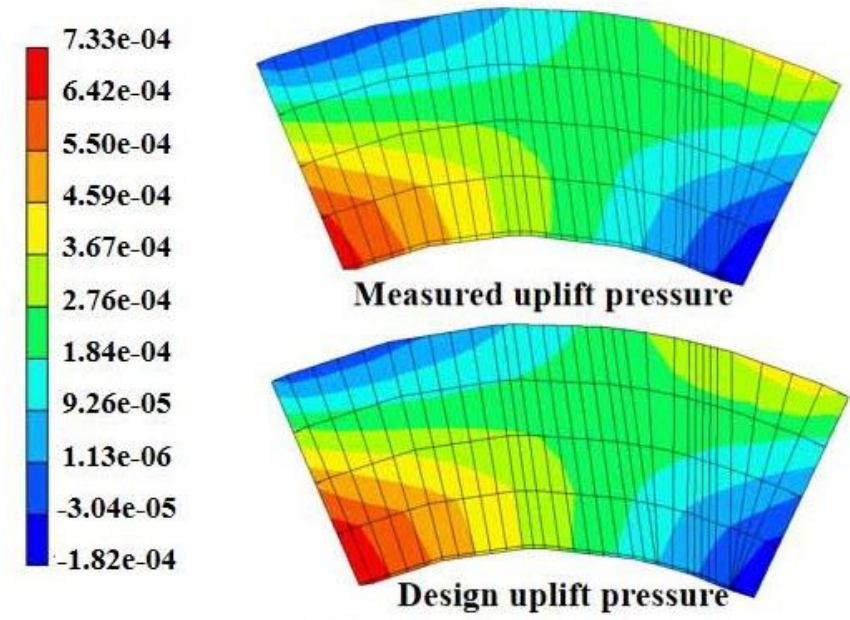

(c) Transverse displacement

Figure 16. Contour map of foundation displacement under the measured uplift pressure (Unit: $\mathrm{m}$ ).

The displacement distribution under the measured uplift pressure conforms to the general law, and the change of uplift pressure has little effect on the safety and stability of the dam body. The FEM results show that the dam deformation is still relatively safe under the abnormal uplift pressure.

According to the analysis of the structural behavior of the arch dam under the abnormal uplift pressure, the stress and deformation of this concrete arch dam are still within the allowable safety range of the concrete material. Meanwhile, the structural behavior of this 
dam meets expectations in a short time. However, the monitoring of the uplift pressure should be strengthened, and attention should be paid to the development of abnormal uplift pressure value and its scope. The operation should avoid the high water level as much as possible and deal with the leakage of the dam foundation as soon as possible to ensure the safety of the concrete arch dam.

\section{Conclusions}

Aiming at the abnormal uplift pressure of concrete dams, this essay has discussed the anomaly identification, uplift pressure application method, structural numerical simulation, and structural diagnosis of concrete dams around the data processing and analysis of abnormal uplift pressure. This study has shown that:

(1) An intelligent anomaly identification model of uplift pressure, based on DBSCAN, is constructed. Because the uplift pressure is closely related to the reservoir water level, the DBSCAN can precisely identify the monitoring data clustering of the uplift pressure in the normal and the abnormally stable state. Therefore, the Densitybased clustering methods, such as the DBSCAN, have good applicability for the identification of abnormal uplift pressure data.

(2) There is still no unified understanding of applying the lifting pressure in the FEM, but the analysis of the structural behavior of concrete dams is partially safe with the face force application method. Then, a measured uplift pressure application method is proposed to accurately reflect the spatial distribution and abnormal position of uplift pressure. Meanwhile, self-written software is compiled, enabling users to complete the uplift pressure application quickly.

(3) Comparing the structural behavior, under the designed and measured uplift pressure, the influence extent and scope of abnormal uplift pressure on the concrete dam is clear. For those reservoirs that cannot be stopped immediately and thoroughly, the safety of concrete dams is evaluated accurately and reasonably using this method, which is of great significance to ensure the project's safety and maximize the social benefits.

Taking a $100 \mathrm{~m}$ concrete arch dam in western China as an example, a series of studies on the structural diagnosis of the concrete arch dam was carried out from the anomaly identification, cause analysis, FEM simulation, and influence analysis, verifying the feasibility of the above analysis ideas and calculation methods. This study provides the comprehensive assessment of dam safety under abnormal uplift pressure, which had important scientific research and practical engineering significance for the safe operation of concrete structures.

Author Contributions: Conceptualization, C.M.; methodology, C.M.; software, C.M.; validation, T.Z.; resources, T.Z..; data curation, G.L.; writing-original draft preparation, C.M.; writing-review and editing, A.Z.; supervision, L.C.; funding acquisition, L.C. All authors have read and agreed to the published version of the manuscript.

Funding: This research was funded by the National Natural Science Foundation of China [51809212] Joint Funds of Natural Science Fundamental Research Program of Shaanxi Province of China and the Hanjiang-to-Weihe River Valley Water Diversion Project, grant number [2019JLM-55] and the Doctoral Foundation of Xi'an University of Technology, grant number [104-451121003].

Institutional Review Board Statement: Not applicable.

Informed Consent Statement: Not applicable.

Data Availability Statement: Not applicable.

Acknowledgments: The authors are grateful to Xudong Qu for the information about the arch dam.

Conflicts of Interest: The authors declare no conflict of interest. 


\section{References}

1. Hanna, A.W.; Plewes, H.D.; Wong, R.; Seyers, W.C. Investigations of high uplift pressures beneath a concrete dam. Can. Geotech. J. 1993, 30, 974-990. [CrossRef]

2. Li, B.; Yang, J.; Hu, D.X. Dam monitoring data analysis methods: A literature review. Struct. Control Health Monit. 2020, 27, e2501.1-e2501.14. [CrossRef]

3. Kang, F.; Li, J.; Xu, Q. Structural inverse analysis by hybrid simplex artificial bee colony algorithms. Comput. Struct. 2009, 87, 861-870. [CrossRef]

4. Le, J.L. Size effect on reliability indices and safety factors of quasibrittle structures. Struct. Saf. 2015, 52, 20-28. [CrossRef]

5. Zhang, G.D. Seepage pressure of concrete gravity dam. J. Hydraul. Eng. ASCE 1956, 1, 59-70. (In Chinese)

6. Pereira, R.; Batista, A.L.; Neves, L.C.; Casaca, J.M. A priori uplift pressure model for concrete dam foundations based on piezometric monitoring data. Struct. Infrastruct. Eng. 2020, 17, 1523-1534. [CrossRef]

7. Rochon-Cyr, M.; Leger, P. Shake table sliding response of a gravity dam model including water uplift pressure. Eng. Struct. 2009, 31, 1625-1633. [CrossRef]

8. Plizzari, G.A. On the influence of uplift pressure in concrete gravity dams. Eng. Fract. Mech. 1998, 59, 253-267. [CrossRef]

9. Pekau, O.A.; Zhu, X.Y. Effect of seismic uplift pressure on the behavior of concrete gravity dams with a penetrated crack. J. Eng. Mech. 2008, 134, 991-999. [CrossRef]

10. Alliard, P.M.; Leger, P. Earthquake safety evaluation of gravity dams considering aftershocks and reduced drainage efficiency. $J$. Eng. Mech. 2008, 134, 12-22. [CrossRef]

11. Javanmardi, F.; Leger, P.; Tinawi, R. Seismic structural stability of concrete gravity dams considering transient uplift pressures in cracks. Eng. Struct. 2005, 27, 616-628. [CrossRef]

12. Mostafaei, H.; Gilani, M.S.; Ghaemian, M. Stability analysis of arch dam abutments due to seismic loading. Sci. Iran 2017, 24, 467-475. [CrossRef]

13. Liu, X.; Wang, S.; Wang, E. A study on the uplift mechanism of Tongjiezi dam using a coupled hydro-mechanical model. Eng. Geol. 2011, 117, 134-150. [CrossRef]

14. Ganji, H.T.; Alembagheri, M. Stability of monolithic gravity dam located on heterogeneous rock foundation. Arab. J. Sci. Eng. 2017, 43, 1-17. [CrossRef]

15. Chen, J.Y.; Zhang, L.; Chen, Y.A.; Yang, B.Q.; Ding, Z.L. Equivalent method for Simulating Uplift Pressure in dam model test. Adv. Struct. Eng. 2010, 13, 1063-1073. [CrossRef]

16. Fu, C.J.; Yao, X.W.; Li, T.; Shen, H.Y.; Wang, Z.Y.; Jiang, J.Q. Investigation and evaluation of increasing uplift pressure in an arch dam: A case study of the Huaguangtan Dam. KSCE J. Civ. Eng. 2014, 18, 1858-1867. [CrossRef]

17. Shu, H.H.; Zhou, Y.M. Coupling analysis of stress and seepage in unsaturated porous media. Water Conserv. Sci. Technol. Econ. 2017, 23, 20-23. (In Chinese)

18. Ghorbani, M.; Sharifzadeh, M. Long term stability assessment of siah bisheh powerhouse cavern based on displacement back analysis method. Tunn. Undergr. Space Technol. 2009, 24, 574-583. [CrossRef]

19. Salazar, F.; Conde, A.; Irazabal, J.; Vicente, D.J. Anomaly Detection in Dam Behaviour with Machine Learning Classification Models. Water. 2021, 13, 2387. [CrossRef]

20. Zhu, S.Y.; Li, Y.L.; Lu, X.; Liu, K.X. Study on anomaly identification method for security monitoring data based on membership cloud. Yangtze River 2021, 52, 197-200. (In Chinese)

21. Hu, J.; Ma, F.H.; Wu, S.H. Anomaly identification of foundation uplift pressures of gravity dams based on DTW and LOF. Struct. Control Health Monit. 2018, 25, e2153. [CrossRef]

22. Hu, J.; Ma, F.H. Comprehensive investigation method for sudden increases of uplift pressures beneath gravity dams: Case study. J. Perform. Constr. Facil. 2016, 30, 04016023. [CrossRef]

23. Park, C.M. Dam sensor outlier detection using mixed prediction model and supervised learning. Int. J. Adv. Smart Converg. 2018, 7, 24-32.

24. Li, X.; Li, Y.L.; Lu, X.; Wang, Y.F.; Zhang, H.; Zhang, P. An online anomaly recognition and early warning model for dam safety monitoring data. Struct. Health Monit. 2020, 19, 796-809. [CrossRef]

25. Salazar, F.; Toledo, M.A.; Gonzalez, J.M.; Onate, E. Early detection of anomalies in dam performance: A methodology based on boosted regression trees. Struct. Control Health Monit. 2017, 24, e2012. [CrossRef]

26. Su, Y.; Weng, K.L.; Lin, C.; Chen, Z.Q. Dam deformation interpretation and prediction based on a long short-term memory model coupled with an attention mechanism. Appl. Sci. 2021, 11, 6625. [CrossRef]

27. Cheng, L.; Zheng, D.J. Two online dam safety monitoring models based on the process of extracting environmental effect. Adv. Eng. Softw. 2013, 57, 48-56. [CrossRef]

28. Li, X.; Wen, Z.P.; Su, H.Z. An approach using random forest intelligent algorithm to construct a monitoring model for dam safety. Eng. Comput. 2021, 37, 39-56. [CrossRef]

29. Zhu, K.; Gu, C.S.; Qiu, J.C.; Li, H. The analysis of the concrete gravity dam's foundation uplift pressure under the function of typhoon. Math. Probl. Eng. 2016, 2016, 1-9. [CrossRef]

30. Granrut, M.D.; Simon, A.; Dias, D. Artificial neural networks for the interpretation of piezometric levels at the rock-concrete interface of arch dams. Eng. Struct. 2019, 178, 616-634. [CrossRef] 
31. Ester, M.; Kriegel, H.P.; Sander, J.; Xu, X.W. A density-based algorithm for discovering clusters in large spatial databases with noise. AAAI Press 1996, 96, 226-231.

32. Lee, H.T.; Lee, J.S.; Yang, H.; Cho, I.S. An ais data-driven approach to analyze the pattern of ship trajectories in ports using the dbscan algorithm. Appl. Sci. 2021, 11, 799. [CrossRef]

33. Ijaz, M.F.; Alfian, G.; Syafrudin, M.; Rhee, J. Hybrid prediction model for type 2 diabetes and hypertension using dbscan-based outlier detection, synthetic minority over sampling technique (smote), and random forest. Appl. Sci. 2018, 8, 1325. [CrossRef]

34. Saiz-Manzanares, M.C.; Rodriguez-Diez, J.J.; Diez-Pastor, J.F.; Rodriguez-Arribas, S.; Marticorena-Sanchez, R.; Ji, Y.P. Monitoring of student learning in learning management systems: An application of educational data mining techniques. Appl. Sci. 2021, 11, 2677. [CrossRef]

35. Li, S.; Pan, J.W.; Luo, G.H.; Wang, J.T. Automatic modal parameter identification of high arch dams: Feasibility verification. Earthq. Eng. Eng. Vib. 2020, 19, 953-965. [CrossRef]

36. Askari, S. Fuzzy c-means clustering algorithm for data with unequal cluster sizes and contaminated with noise and outliers: Review and development. Expert Syst. Appl. 2021, 165, 113856. [CrossRef]

37. Liu, X.; Ding, Y.; Tang, H.; Xiao, F. A data mining-based framework for the identification of daily electricity usage patterns and anomaly detection in building electricity consumption data. Energy Build. 2021, 231, 110601. [CrossRef]

38. Cheng, Z.F.; Wang, X.L.; Ren, B.T.; Lv, P.; Zhu, X.B. Simulation of complex seepage field of a gravity dam foundation using a CFD-based approach. J. Hydraul. Eng. 2018, 144, 05018001. [CrossRef]

39. Heidarzadeh, M.; Mirghasemi, A.A.; Niroomand, H. Construction of relief wells under artesian flow conditions at dam toes: Engineering experiences from Karkheh earth dam, Iran. Int. J. Civ. Eng. 2015, 13, 73-80.

40. BAO, T.F.; Gu, C.S.; Wu, Z.R. Analysis of uplift pressure anomaly of Lijiaxia dam foundation. Chin. J. Geotech. Eng. 2008, 30, 1460-1466. (In Chinese)

41. Saberhosseini, S.E.; Keshavarzi, R.; Ahangari, K. A fully coupled numerical modeling to investigate the role of rock thermomechanical properties on reservoir uplifting in steam assisted gravity drainage. Arab. J. Geoences 2017, 10, 1-10. [CrossRef]

42. Gan, L.; Shen, Z.Z.; Wang, R.; Huang, Q.F. Stress-seepage fully coupling model for high arch dam. Appl. Mech. Mater. 2014, 513, 4025-4029. [CrossRef]

43. Roth, S.N.; Leger, P.; Soulaimani, A. Fully-coupled hydro-mechanical cracking using xfem in $3 \mathrm{~d}$ for application to complex flow in discontinuities including drainage system. Comput. Meth. Appl. Mech. Eng. 2020, 370, 113282. [CrossRef]

44. Li, M.C.; Guo, X.Y.; Shi, J.; Zhu, Z.B. Seepage and stress analysis of anti-seepage structures constructed with different concrete materials in an RCC gravity dam. Water Sci. Eng. 2015, 8, 326-334. [CrossRef]

45. Lin, J.Y. Hydraulic Building, 5th ed.; China Water \& Power Press: Beijing, China, 2009. (In Chinese)

46. Peng, Y.F. Calculation and control of seepage of hardfill dam with different foundation. Adv. Mater. Res. 2011, 255, 3666-3670. [CrossRef] 